Chapter 4

\title{
Emerging Patterns of Grassroots Innovations: Results of a Conceptual Study Based on Selected Cases from India
}

\author{
By: Anup Karath Nair ${ }^{1}$, Rajnish Tiwari ${ }^{2}$ and Stephan Buse ${ }^{3}$
}

\begin{abstract}
Among all the innovation strategies that seek to impact developing economies, Grassroots Innovation remains the least explored. With critics of Bottom of the Pyramid literature articulating the need for considering the poor as producers, a better understanding of the grassroots phenomenon may help companies to understand and integrate the Grassroots Innovation strategy into their business models and thereby allowing the poor to become producers of products and solutions. This study examines the dimensions and trends, which make Grassroots Innovations unique, as well as factors which govern and influence them.

The study is based on in-depth case studies which were gathered during field work with the National Innovation Foundation in India. The data illustrates how factors like education, age, occupation and sector influence the triggers and the outcomes of Grassroots Innovations. It also demonstrates how individuals, institutions and firms could collaborate to commercialize these products and solutions.
\end{abstract}

Keywords: Grassroots Innovations, India, Bottom of the Pyramid, innovation bricolage, frugal innovation

\footnotetext{
${ }^{1}$ Corresponding author; University of Strathclyde; anup.k.nair@strath.ac.uk

${ }^{2}$ Hamburg University of Technology; tiwari@tuhh.de

${ }^{3}$ Hamburg University of Technology; stephan.buse@tuhh.de
} 


\section{Introduction}

Innovations from developing economies have been the subject of intense scrutiny and debate (see, e.g., Agtmael, 2007; Immelt, Govindarajan, and Trimble, 2009; Prahalad and Mashelkar, 2010; Schumann, 2010; Schanz, Hüsig, Dowling, and Gerybadze, 2011; Von Zedtwitz, Corsi, Søberg, and Frega, 2015). There exists a variety of literature on low-cost innovations and innovations emanating from emerging markets. Various terms such as "Bottom of the Pyramid" (BOP) Innovations (Prahalad and Hart, 2002), Frugal Innovations (Tiwari, Kalogerakis, and Herstatt, 2016), Gandhian Innovations (Prahalad and Mashelkar, 2010), Jugaad (Radjou, Prabhu, and Ahuja, 2012), "Low-cost, high tech" innovations (Schanz et al, 2011) and Reverse Innovations (Immelt et al, 2009) have entered the innovation lexicon in a relatively short space of time. The surrounding rhapsody has caused a phenomenon called Grassroots Innovations to go relatively unnoticed.

Grassroots Innovations generally refer to products developed by "economically poor but knowledge rich people" who are disconnected from formal market ecosystems, but are able to creatively deploy their indigenous skills and local knowledge (Gupta, 2010). Although several scholars have based their analyses on the psychological, sociological, agricultural sciences and policy dimensions of Grassroots Innovations, as will be demonstrated later, so far not much attention has been paid to it from the perspective of innovation management, except for a few recent, notable exceptions such as by Praceus (2014), Praceus and Herstatt (2014), and Krämer (2015). As a result, we continue to have limited understanding of how entrepreneurial actors can capitalize on indigenous knowledge and creativity and transform it into tools for revenue generation and inclusive economic development.

The primary focus of this paper is to study Grassroots Innovations through the lens of innovation management literature. The first segment of this study deals with the definitional aspects of Grassroots Innovations. Due to the limited availability of academic research, Grassroots Innovations have often been clubbed along with BOP Innovations and Frugal Innovations despite having their own unique flavors which distinguishes them (Tiwari and Herstatt, 2014). It is therefore essential for us to analyze these different categories of innovations and highlight the differences.

The second segment, explores the phenomenon of Grassroots Innovations in greater depth. In this segment, we introduce the concept of "innovation bricolage" by blending theory from the 
field of anthropology. This conceptualization allows us to classify the various processes involved in Grassroots Innovations. The primary data from a variety of Grassroots Innovation endeavors are closely examined in more specific contexts. This information is then synthesized to identify the parameters influencing the innovations.

All the inputs for this study originate from data gathered from thirty-seven qualitative case studies from India. These cases were documented by Anup Karath Nair during the extensive fieldwork he undertook as an intern with the National Innovation Foundation (NIF) India. This study explores how the Grassroots paradigm might offer a unique model to promote development in which the poor not only play a part, but potentially also assume a leadership role in the creation of 'shared value'.

This paper is organized as follows: Section 2 introduces the definitional framework of Grassroots Innovations, while Section 3 deals with the research methodology. Section 4 contains 4 detailed case studies grassroots innovators. Section 5 characterizes Grassroots Innovations based on a broader, more generalizable data sample. This is followed by section 6 which discusses the implications of the study and concludes with a summary.

\section{Definitional Framework of Grassroots Innovations}

Since the beginning of this century, "micro innovations" which can produce "macro results" (Wood and Hamel, 2002) are being recognized as new ways to advance the cause of economic prosperity. The view that engaging the poor in increased economic activity can help them become an engine of economic growth for the poor is increasingly gaining attention (Prahalad and Hammond, 2002; Prahalad and Hart, 2002; Seelos and Mair, 2007). However, so far the participation of the poor in the development process has been limited. In words of Anil K. Gupta (2000: 20): "Not only is there little opportunity for them to articulate their ideas, there is seldom an institutional space where their ingenuity and creativity in solving their problems can be recognized, respected and rewarded".

Several reasons exist why the participation of the poor in the development process is limited. Globally, the poor, especially those in rural areas, suffer from market access disadvantages that affect both the inbound and out-bound flow of goods and services, creating an adverse effect on "the rural population's income and quality of life" (Vachani and Smith, 2008: 53). In fact "limited local demand, combined with the high cost of transporting goods, to and 
from remote villages, depresses farmers' incomes and results in higher prices for the agricultural inputs and consumer goods they acquire from urban areas" (Vachani and Smith, 2008: 54). Weak infrastructure which includes poor roads, inadequate telecom services and disrupted electricity supply as well as lack of information combined with, inadequate knowledge and skills and widespread illiteracy all impede market access. Furthermore, three broad types of institutional voids negatively impact the market participation among the poor: institutional voids impairing market functioning (Leff, 1978; Khanna and Palepu, 2000), institutional voids hampering market development (Polanyi, 1994; Woodruff, 1999) and institutional voids impeding market participation (Mair and Marti, 2009). These conditions constitute the breeding ground for Grassroots Innovations.

\subsection{Review of Literature on Grassroots Innovations}

Grassroots innovations are a nebulous field as far as academic research is concerned and there are several schools of thought influencing theory building in this field. In order to trace the theory behind Grassroots Innovation, an extensive literature review was undertaken. The key words used include "grassroots innovation", "grassroot innovation" and various permutations and combinations of these keywords. This search yielded 34 publications. In a next step, the articles were then classified as relevant or irrelevant to the subject by reading their respective abstracts.

Of these 34 articles, 23 were found to be both relevant as well as available for an analysis. These included 2 book chapters, 13 journal articles, 5 conference papers, and 3 working papers. An analysis of contributions by the authors involved in the 23 entries showed that Anil K. Gupta was the leading voice in the field followed by Adrian Smith.

All bibliographical references in these 23 articles were then keyed-in in a Microsoft Excel database to further analyze the origin of theory resulting in 302 unique entries. The number of citations of these references was recorded to analyze the impact of the work's contribution towards theory. Self-edited and self-cited entries were filtered out reducing the list to 136 unique results. These results were then further classified based upon the title of the article and the journals in which they were published, where applicable. During the classification, preference was first given to the Journal title and then to the title of the article. As a result, ten unique streams were identified (see Figure 1). It seems that policy and social factors have so far been the most-important factors of influence in the research on Grassroots Innovations. 


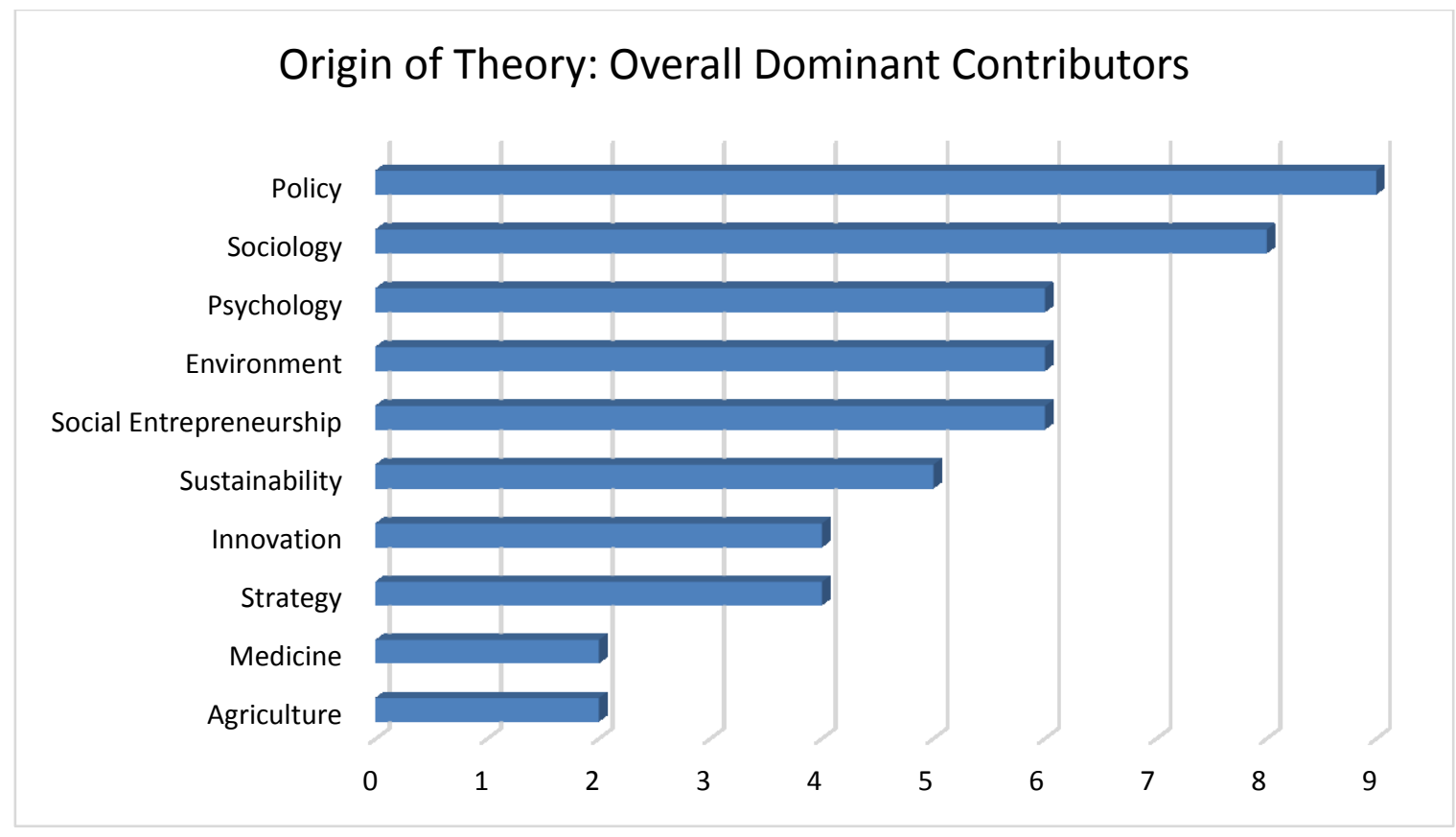

Figure 1: Origin of Theory: Overall Dominant Contributors

An analysis of the most cited authors was also carried out, which brought up some interesting results. The highest number of citations was 6 , which was shared by four authors. Adrian Smith emerges as the only author who not only focuses on Grassroots Innovation but also significantly contributes to its theory building (see Figure 2).

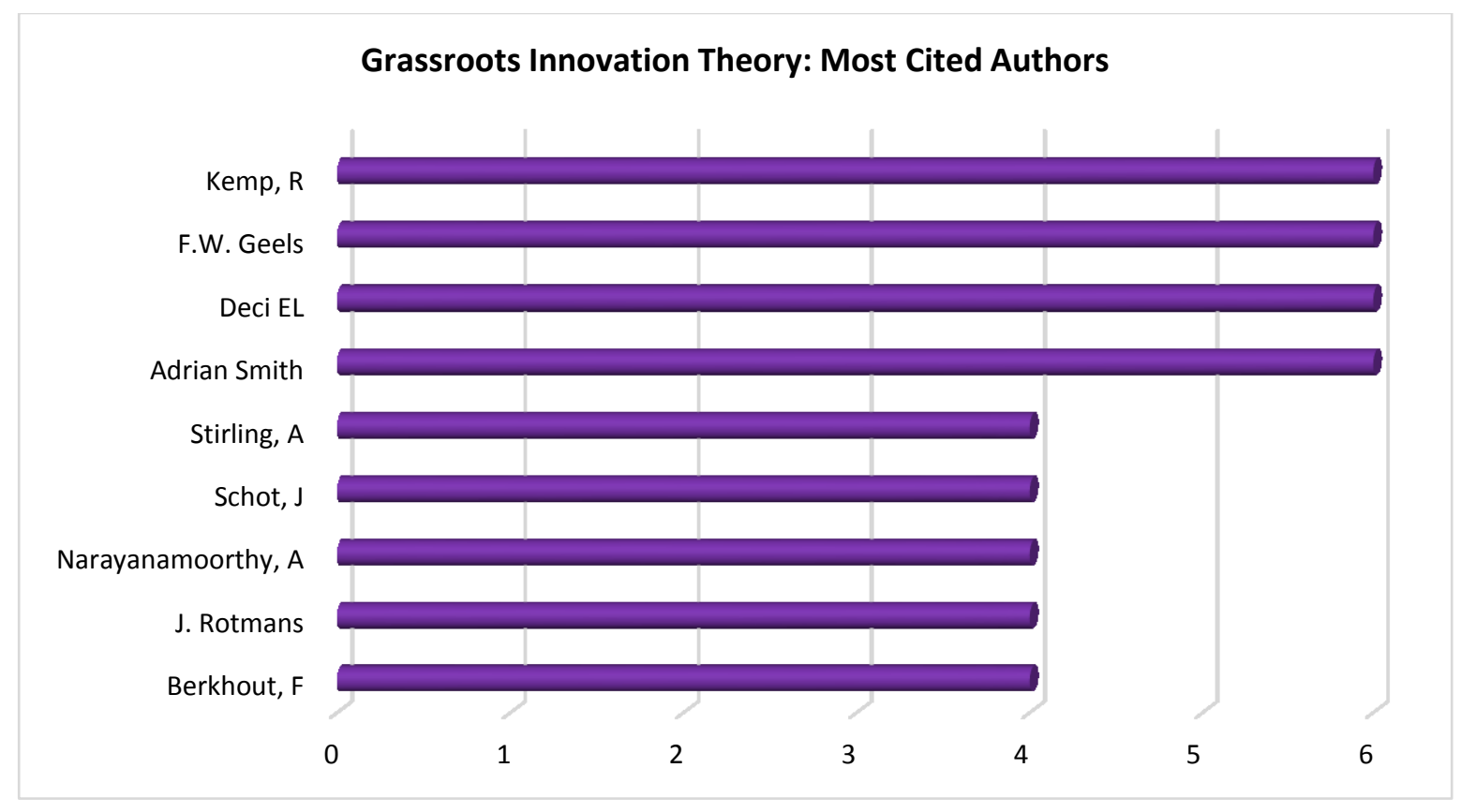

Figure 2: Most-cited Authors in the Literature on Grassroots Innovations

Among the most cited authors, Adrian Smith's research revolves around policies impacting environment and sustainability (see, e.g., Smith, 2006). Kemp researches environmental 
issues (see, e.g., Kemp and Rotmans, 2005), Deci has contributed to psychology and motivation theories (see, e.g., Deci, 1971) and Geels' research incorporates flavors of innovation and sociology (see, e.g., Geels, 2004).

\subsection{Philosophy of Grassroots Innovations}

"The enormous upsurge of creativity at grassroots demonstrates to the positive energy that has been locked up due to institutional inertia over several decades and centuries" (Gupta, Sinha, Koradia, Patel et al, 2003: 984). Yet, the potential for a knowledge intensive approach to promote economic development has rarely been explored (Gupta et al, 2003; Gupta, 2010). The possibilities that "the knowledge of the marginalized people may become a new counter point" (Gupta et al, 2003: 977) while dealing with issues pertaining to economic and environmental sustainability has yet to gain steam to fully realize its potential.

By grassroots innovations, we refer to the products developed by the economically poor people who are disconnected from formal market ecosystems, but successfully and creatively deploy their indigenous skills and local knowledge. One of the significant features of grassroots innovations is the context of the innovation itself. The reality is that even though grassroots innovation may be easy to grasp at a subjective level, yet its definition is riddled with several complexities.

This is because Grassroots Innovations are mostly minor or incremental changes to existing technological products making them better suited to local needs. Thus, the conventional definition of innovation, which emphasizes the complete newness or significant improvements (cf. OECD and Eurostat, 2005), is ill suited to define grassroots innovations. In spite the fact that grassroots innovations blend a lot of local, contextual and traditional knowledge to modify mainstream modern technologies, the innovativeness of this activity has rarely been acknowledged (Gupta et al, 2003; Seyfang and Smith, 2007; Gupta, 2010). A major reason for this contradiction is because grassroots innovations and commercialization; two important strands for decentralized, dispersed economic entrepreneurship have not hitherto been linked.

Seyfang and Smith (2007: 585) have attempted to circumvent the shortcomings of the conventional understanding of innovation by defining Grassroots Innovations as:

"Networks of activists and organizations generating novel bottom up solutions for sustainable development: solutions that respond to the local situation and the interests and values of the communities involved." 
This definition originates from the attempt to bridge innovation with community action in the context of sustainability. However, even though this definition emphasizes on how grassroots niche innovations differ from mainstream business innovations and highlights most of its features, it seems to neglect the role of markets and individual innovators in grassroots innovations, thereby confining grassroots innovations, to the social economy of community activities and social enterprise.

Yet another definition of grassroots innovations was proposed by (Bhaduri and Kumar, 2009: $3)$ :

"The term grassroots refer to individual innovators, who often undertake innovative efforts to solve localized problems, and generally work outside the realm of formal organizations like business firms or research institutes."

Furthermore, Bhaduri and Kumar (2009: 5) see grassroots innovations representing "a complex set of socio-political and economic aspiration of people, who normally bank on their skills and practical experience, rather than formal body of technical knowledge, to carry out technological activities."

The third definition of grassroots innovation emerges indirectly from the field of social entrepreneurship in words of Masse and Dorst (2007: 3), who describe grassroots social entrepreneurs as "citizens with an innovative idea to solve a social problem, but without an existing organization backing them". This definition would imply that grassroots innovations are those innovative products and services by social entrepreneurs that seek to solve problems while operating in the informal sector. While it may be true that grassroots innovators solve social problems but as rightly pointed by Anil Gupta et al (2003), grassroots innovators sometime may not like to become entrepreneurs themselves. Therefore, defining grassroots innovations by blending social entrepreneurship with innovation poses a deficiency which could limit our understanding of the phenomenon and its potentials.

Before describing any innovation, the first step should be to consider the question of perspective (Abernathy and Clark, 1985). Understanding grassroots innovations depends on a sound understanding of localized contexts in which these innovations are rooted. Many inhabitants of these areas "live in poverty and relative isolation: their local products are unfamiliar in most of the world, their public infrastructures are weak, and their skills are unrecognized" (Gupta, 2006: 49). Formal markets and institutions usually do not find solutions for the highly localized problems faced by people in these regions (Gupta, Sinha, 
Koradia, Prakash et al, 2001), as has been also pointed by some researchers in a critique of the BOP paradigm (Karnani, 2007; Karamchandani, Kubzansky, and Lalwani, 2011).

Subsistence is "a constant challenge" in these regions, as Gupta (2006: 49) points out: "Local individuals and tribal communities have long met those challenges by drawing on their local environments, inventing effective agricultural techniques. [...] Harsh conditions have done as much to induce individual creativity and innovation as to limit them". Not surprisingly, every now and then, an innovative solution emerges to solve some problem of day-to-day life (Gupta et al, 2001). Such innovations, then, "may be based on traditional knowledge and resources or emanate from an entirely contemporary context" (Gupta et al, 2001: 7), and due to their context-specific, focused and resource-efficient approach may be regarded as “appropriate technologies" (Schumacher, 1973; Stewart, 1987; Grieve, 2004; Kaplinsky, 2011). Such appropriate solutions, leading to minor or incremental innovations, "are most commonly observed in technologically backward countries primarily to make an existing technology suit better in an environment, where market size is small, capital scarcity is high, and preference for novelty is relatively low" (Bhaduri and Kumar, 2009: 4). According to Tiwari (2011: 17) "many local users in rural areas come up with inventions that are not only innovative and useful but also less expensive than the usual solutions available in the market". Another important feature of grassroots innovations is that they are generally "environment friendly and in sync with the given infrastructural conditions" (Tiwari, 2011). We, therefore, propose to define grassroots innovations from this perspective and propose the following framework:

Grassroots innovations are products developed by people endowed with technical or traditional knowledge but disconnected from formal market systems. The inventors and potential customers need not necessarily be poor but are generally located in rural and/or semi-urban areas. The market size for such products can be large but fragmented, capital scarcity tends to be high, while need for novelty is relatively low. The inventors make a creative deployment of their indigenous skills and local knowledge.

The above definition is important, because it allows us to conceptualize the grassroots innovation processes around a concept called bricolage, which was first introduced by anthropologist Levi-Strauss (1966) and has found application in research on innovation management in resource-constrained environments (Baker, Miner, and Eesley, 2003; Garud and Karnøe, 2003; Baker and Nelson, 2005; Tiwari, Fischer, and Kalogerakis, 2016). Our present study adopts the term "bricolage" to describe the process of "making do" by 
recombining elements at hand (Mair and Marti, 2007). We argue that grassroots innovations can be thought of as 'innovation bricolage' because the innovators often make do with the resources and institutions at hand.

As a result, the process of grassroots innovation is often participative allowing individuals and communities to "benefit in terms of greater empowerment and confidence, skills and capacity" (Seyfang and Smith, 2007: 595) to enable market participation. Grassroots creativity can thus be used to "harness global capital and entrepreneurial support for decentralized development" (Gupta et al, 2003: 984). Since grassroots innovators are constantly making the trade-offs between accuracy, affordability, accessibility and local adaptability (Gupta, 2010), their knowledge and innovations can be utilized by firms to customize their products and technological portfolios. Therefore, the grassroots paradigm provides firms not only with a large surface area for experimentation but also access to previously untapped markets.

Seelos and Mair (2007) point to works by London and Hart (2004) who have posited that MNCs need to re-equip their strategy tool kits by rethinking not just how they manage their resources "but also to develop and acquire new resources and capabilities and forge a multitude of relationships and alliances with local non-traditional BOP partners" (Seelos and Mair, 2007: 51). Seelos and Mair (2007) also refer to works by Hart and Sharma (2004) who have called for "the development of radically new capabilities and proposed the use of laboratories to bring about new business models that account for the concerns of fringe stakeholders, i.e. local customers and activist groups" (Seelos and Mair, 2007: 51). We will argue that grassroots strategy is an efficient means by which firms can "draw upon the experimental reserve that local community or individual knowledge experts have already accumulated through their own struggles in the past" (Gupta, 2000).

\section{Methodology and Research Objectives}

The data for this study was gathered between June 2010 and September 2010 when firstauthor, Anup Karath Nair, worked at the National Innovation Foundation, (NIF) India, as a summer intern. The NIF, as per information available on its webpage was established by the Ministry of Science and Technology, Government of India in year 2000 with the "main goal of providing institutional support in scouting, spawning, sustaining and scaling up grassroots green innovations and helping their transition to self-supporting activities". 
Of the 37 samples of grassroots innovations which were investigated for this study, the author personally gathered data for 16 cases. Anup Karath Nair travelled through the Indian states of Gujarat, Kerala and Tamil Nadu to meet the grassroots innovators. Data was gathered through a questioner which captured the respondents' views pertaining to various aspects of innovation. To make the exercise representative and robust, all the innovators were interviewed at their respective innovation sites. A phenomenological approach (Davis, 1971) was adopted in order to capture the reality as perceived by the grassroots innovators. The remaining 21 innovations were selected from similar scouting and documentation reports carried out by two other Summer Interns at the NIF.

In addition to these interviews objective data, such as sales figures, was also sought from the innovators. The responses from the innovators were transcribed on the questionnaire. Photographs and video recordings of the innovations were made for future references. Furthermore, secondary data was gathered from various media sources including the internet.

All the innovators were required to sign a Prior Informed Consent (PIC) which allows NIF to use their data/knowledge for academic/commercialization purposes. Pictures of the innovations and the videos capturing the work have been recorded and shared with the NIF where it is archived.

A combination of narrative and visual mapping strategies was deployed to analyze the data of the 37 cases. The narrative approach, in accordance with Maase and Dorst (2010: 186), was "used as a preliminary step aimed at preparing a chronological overview of what happened over time". This technique is particularly useful while writing the case studies selected to highlight the 'grassroots innovations' phenomena. Visual mapping was used to "compare and identify patterns" in the innovation process (Maase and Dorst, 2010: 186). The case cluster method allowed us to compile objective data from the field work. The objective data was statistically analyzed to identify patterns of innovation. This analysis fuels the discussion section where some of the findings can be linked to propositions, statements and themes of the literature review. A more detailed presentation of the cases than in this paper has been made available in a working paper, published as Nair, Tiwari and Buse (2012). 


\section{Case Studies of Grassroots Inventors}

In this segment, four detailed case studies are presented to highlight the complexities in the origin, process and evolution of the phenomenon called grassroots innovations.

\subsection{Case Study A: Mansukhbhai Prajapati}

Mansukhbhai Prajapati hails from the Western Indian state of Gujarat. He lives in a small village called Wankaner near a town called Morbi. Rajkot is the closest city. Morbi is one of the leading ceramic tiles manufacturing hubs in India manufacturing about $70 \%$ of the total Indian ceramic production and home to more than 390 manufacturing units. Mansukhbhai Prajapati was 44 years old at the time of interview and a potter by profession. He lives with his wife and two sons. His parents were also potters who in addition worked as masons laying bricks for a living. Financial constraints on the family forced him to drop out of school when he was in the $10^{\text {th }}$ Standard. After this he was employed at one of the local ceramic tile factories for 5 years where he earned a wage of $\mathbf{₹} 300$ (approximately $€ 5$ ) a month.

In the year 1989, Mansukhbhai quit his job at the tiles factory after a minor disagreement with the management. Without a job and a livelihood, he decided to utilize his skills as a potter to earn a living. In those days, he recalls witnessing a need for clay pans (called tawa) which the village folk used to cook their daily meals. Being a potter and with the baking skills he had acquired during his stint at the ceramics factory, Mansukhbhai focussed on baking and selling clay pans for as less as $\mathbf{₹} 3$ (approx. € 0.05) a day. This venture was funded by a local private money lender who Mansukhbhai was acquainted with from his factory days. He recalls paying an interest rate of $1 \%$ per day.

Obviously, these pans were low in quality and need to be replaced every 15 days. All the competing clay pans in the villages were roughly the same quality. This was when Mansukhbhai first thought of improving the quality of his product. The experiences he gained while manufacturing the pans enabled him to realize that the clay was not being pressurized into consistent thickness causing the premature breakage of the pans. This insight motivated him to design a tawa machine.

While the design of the machine was perfected through trial and error, Mansukhbhai was assisted by a local mechanic in Morbi, to build the machine. This mechanic was one of the technicians who are called on to repair faults in the manufacturing units of the local ceramic companies. Mansukhbhai, grew his business from 1989 until 2001 by largely selling his 
tawas to the nearby villages. In 1995, he designed a water filter which was designed on a principle which exploited the porosity of clay but the main business still remained the clay pan.

In the year 2001, Gujarat was devastated by a massive earthquake which caused massive damage to life and property. The local Gujarati newspaper carried a photograph of a pile of broken earthen clay pots designed by potters of the region with a caption reading "The poor man's fridge is broken!" This was a reference to the traditional technique followed in Indian villages where water is stored in earthen clay pots which allows it to remain cool while drinking. The scientific principle that 'evaporation causes cooling' has been blended with traditional aesthetics to design utensils for everyday use.

Reading this caption was a "eureka" moment for Mansuhkbhai. It struck him that he could use his skills as a potter to design a clay chiller which is cooled using water and thus expand his product line. This was when he adopted the brand 'Mitticool' from the Hindustani word "Mitti" which means mud or clay and the English word 'cool' to denote cooling. A clay chiller designed on such a simple scientific principle would have none of the disadvantages of a traditional fridge which was expensive, and required electricity. The merits and demerits of the chillers are summarized in Table 1.

\begin{tabular}{|c|c|}
\hline \multicolumn{2}{|c|}{ Mitticool Chiller } \\
\hline Advantages & Disadvantages \\
\hline $\begin{array}{l}\text { Does not require any electricity } \\
\text { and therefore no recurring cost }\end{array}$ & $\begin{array}{l}>\text { The cooling efficiency decreases in } \\
\text { winters. }\end{array}$ \\
\hline $\begin{array}{l}\text { Food quality does not deteriorate } \\
\text { for up to a week. }\end{array}$ & $>$ It's bulky and difficult to transport. \\
\hline $\begin{array}{l}\text { Locals claim that it better } \\
\text { preserves the original taste of the } \\
\text { fruits and vegetables. }\end{array}$ & $\begin{array}{l}\text { A clay based design means that users } \\
\text { have to regularly clean the interiors to } \\
\text { avoid the growth of fungus. }\end{array}$ \\
\hline$>$ Eco-friendly & \\
\hline
\end{tabular}


Even though Mansukhbhai was buoyed by the success of his new product, his best-selling innovation did not happen until 2005. In 2005, his wife asked him to bring home a non-stick cooking pan. The non-stick pans were gaining popularity among the Indian households as they were easy to clean and consumed less oil while cooking. When Mansukhbhai, enquired the price for a non-stick cook pan and found out that it costed $\mathbf{2} 450$ (approx. $€ 8.0$ ), he instantly knew that he would not be able to afford it. He was also aware that several people who bought his products would not be able to afford a metallic non-stick clay pan and this was the trigger for inventing the Clay non-stick tawa.

Back in 2005, Mansukhbhai had no idea about non-stick material. Neither was he aware about procurement of it, nor did he know a process by which he could coat clay pans. He even attempted to visit the Nirlep factory in Mumbai (financial capital of India). Nirlep was one of the largest selling brands of non-stick cookware in India. He was denied entry into the factory premises, but was able to track the details of a supplier in his home state Gujarat who later would provide him with the non-stick material he required for experimenting. The entire information gathering was done using personal contacts and informal channels.

Having sourced the materials, Mansukhbhai began to apply his previous skills such as spraying and glazing techniques, he had learnt at the ceramics manufacturing plant. He even updated some of these skills to be able to work with the new technologies. After a one-and-ahalf-year struggle, he was able to produce his first non-stick clay tawa. He now sells the tawa for $\mathbf{₹} 100$ (approx. $€ 1.50$ ) and is constantly trying to improve the product features and design based upon feedback from his local customers. The significance of this innovation is best captured in words of Anil Gupta (2008):

\footnotetext{
"When a potter, Mansukhbhai, paints an earthen clay hot plate (tawa) with non-stick Azo Nobel (liquid) akin to Teflon, he makes a non-stick pan available in a dollar which would cost otherwise around 10 dollars (with a metallic base). Scientists at Bombay University Institute of Chemical Technology, one of the leading chemical technology labs in India, find unique property of this new affordable and accessible clay. Because of the porosity of clay plate, the paint gets embedded much better and does not come off as it happens in the metallic surface. The gas consumption is lesser than the aluminum pane and efficiency is much higher than the available panes. Health hazards are reduced whereas the advantage of low fat cooking are achieved in an extremely low cost manner."
} 


\subsection{Case Study B: M. Sadhasivam}

M. Sadhasivam was a forty-five-year-old farmer in Palakkad, a small town in the south Indian state Kerala, at the time of field visit. Kerala is a socially advanced state in India but paradoxically, its economic development has not kept pace with its social development (Parayil, 1996). Sadhasivam, who had won several awards at school science exhibitions, dropped out when he failed his $12^{\text {th }}$ standard exams. He lives in a village named Chittur with his wife and two children.

Being a small time rice farmer in the state of Kerala has several daunting challenges. Kerala has acute labor problems: Shortage of labor and high wage structure; employing a worker then costs ₹250 a day which was approx. $€ 4.20$ and relatively high for Indian standards. This has prompted farmers to rent threshing and harvesting machines. These machines are very expensive and cost in the range of $\mathbf{₹} 2,500,000$ to 4,000,000 (€ 42,000 to 67,000) which make them expensive to own. However, a farmer also has the opportunity to pay $\mathbf{z} 2,000 / \mathrm{hr}$ (approx. $€ 34 / \mathrm{hr}$ ) to rent such a machine. A small scale agriculturist would require to rent the machine for about 13 hours which means, it's going to cost $₹ 26,000 /-$ (approx. $€$ 350) per harvest. However, it is difficult to find a machine for rental at peak season causing potential losses in case of rains or other bad weather conditions. Since most of the farmers in India do not require and cannot afford large machines, Mr Sadhashivan conceived and prototyped a small threshing and harvesting machine.

This machine was entirely conceived, designed and prototyped by the innovator. The entire process lasted for three months, which is fairly quick for grassroots innovations. This machine has several advantages over the existing market solutions. The new device promises a $62.5 \%$ cost reduction which makes it significantly cheaper than the existing products in the market. The existing harvesting and threshing machines cannot be transported by road which makes them more expensive to use during the harvesting season. Machine mobility is one of the significant contributions of this innovation. The wheels allow the farmer to drive the machine on the road to the required site of harvest. The hay collected after harvesting is important to several farming communities in India as they use it to feed their cattle and livestock. Existing harvesting and threshing machines, due to their design destroy the hay. Sadhasivam's prototype on the other hand is designed to harvest and thresh paddy in a manner which retains the hay. Finally, the differential engines used in his design achieve the twin benefits of improved efficiency and reduced fuel consumption. 
Sadhasivam, in 2010, decided to supplement his farm income by selling a tender coconut packaged drink. Coconut palms are abundant in the costal state of Kerala. Sadhasivam distributes this drink in the local market. The efficient production of this drink required several tender coconuts to be split so that the water could be drained and the flesh/pulp removed. Traditionally, this is done by hiring laborers who wield the sickle and de-husk the tender coconut. They then proceed to crack open the nut and drain the water. This process is laborious and time consuming. Besides, as pointed earlier, labor is short and expensive in Kerala. The Tender Coconut Cutter was designed to overcome this problem.

At $₹ 4,000$ (approx. $€ 67$ ) this innovation was entirely conceived and designed by this innovator. He built the device at a local hardware store with technicians executing the design. The innovations were completely funded from the innovator's personal savings. But in order to be able to sell the drink, the innovator was required to ensure its safe packaging. This was the trigger for his subsequent innovation "The Low Cost Packaging Machine".

The drink is packaged into polythene packs which ensure that packaging meets hygiene standards set by the Food Corporation of India. Liquid packaging is used by several juice and shampoo manufacturing companies. It is also used extensively to package milk. Small scale co-operatives and entrepreneurs cannot afford the prices that large scale industrial packaging commands. The low cost equipment currently available in the market costs $\mathbf{₹} 150,000$ (approx. $€ 2,500$ ) and can pack 16 packs/ min. Small scale cottage industry products do not have the money to invest into such a machine, nor do they require to pack 16 packs $/ \mathrm{min}$. The alternative Paddle packing machines are available at $\mathbf{1 5 , 0 0 0}$ (approx. $€ 250$ ) but they are not convenient to use. Hence, the innovator's product not only fulfils his personal need but can also fill a large market need when commercialized.

\subsection{Case Study C: K.S. Sudheer}

K.S. Sudheer was a 48-year-old driver, when he was visited for the purpose of this research. He lived in Ollur, a village in the Thrishur district of Kerala. Sudheer owns an auto rickshaw tempo which he drives to transport goods and earn a living. He has studied until the $10^{\text {th }}$ standard after which he discontinued his education. He lives with his wife and their two children.

Sudheer has previously won a couple of local innovation awards and has always had a keen interest in mechanics. There was an instance where he modified the traditional steering handle of his tempo to incorporate a steering wheel. This made the vehicle easier to control 
and reduced the stress on the driver. But the Regional Transport Office (RTO) which issues licenses and decides who and what vehicles are allowed on the road, refused to recognize this modification and made driving of this vehicle illegal. Even though Sudheer had to forgo this innovation, he retained the same curious enthusiasm for mechanics.

As a driver, the innovator used to transport coconuts. He often used to hear complaints from the coconut workers about aching hands and shoulders. Besides, his wife too needed a quicker technique to de-husk coconuts which is a staple ingredient in many South Indian cuisines. Sudheer, a keen enthusiast in mechanics, designed a series of de-huskers by utilizing the spare parts from an adjoining workshop. There were several delays while working on this project and additionally, time too was a constraint. Sudheer has fallen short of cash on several occasions and at times used up the entire prize money he received during the events which felicitated his innovations to fund his product development. He recalled the technical difficulties he faced while innovating:

"The main technical challenge was the selection of the right kind of spring with adequate tensile strength so that the design functions efficiently."

This points to the deficiency of technical knowledge but remarkably, the innovator has persisted and successfully productized his innovation.

Sudheers' second but even more impressive innovation is the Auto Rickshaw Control for the Limbless. Sudheer poignantly recalls his inspiration for this innovation. His physically challenged friend had recently lost both his legs in an accident. He still has both hands and good upper body strength but no means of livelihood. One afternoon, he requested Sudheer chiding him saying "You have developed several innovations some of which have benefitted our community but could you ever make something which will ensure my livelihood?"

This conversation inspired Sudheer to innovate and develop a device which ensures that he can drive an auto rickshaw, which can be totally controlled by his hands. This original innovation was invented in December 2009 and its operation was successfully demonstrated at several public forums and received a lot of appreciation.

The device acts like a normal auto rickshaw handle but differs in the fact that the mass cylinder which contains the fluid used to activate the breaks is situated on the top of the handle. Pressing the handle, down causes the fluid to be released causing the breaks to operate. This would bring the vehicle to a halt. The major technical challenge faced by the innovator was to perfect the fluid breaking system. It required several adjustments before it 
could work properly. The lack of formal technical knowledge meant that the innovator had to incur a substantially higher cost to innovate. The 'hit and trial' methods deployed meant that a lot of time was wasted on techniques which weren't useful.

\subsection{Case Study D: S. Rajamani}

S Rajamani was a 46 years old cassava farmer at the time of our interview. He lived in Attur, a village in the Salem district of the south Indian state Tamil Nadu. Tapioca, yam and cassava are the staple crops grown in this region. Sago rice derived from cassava is the main diet for most locals in this region. Rajamani has studied until the $12^{\text {th }}$ Standard and now lives with his wife and their three children.

The procurement price of the cassava crop is dependent on the starch content of the random sample being tested. The traditional manual process of determining the starch content is cumbersome and riddled with inaccuracies. In the most widely prevalent measurement process, the cassava is put into a bucket and the weight on the pan is balanced and the scale is locked. The tuber is then immersed in water and the lower point scale is adjusted until the balance is re-established. The reading on the point scale reveals the starch content of the tuber. This method is called the Reinmann Density Method. In these machines, the scales are directly graduated in percentage of starch.

During the crop auction, a farmer is paid for the quality of his products. Since the manual process is time consuming, only a small sample is tested and the whole procurement is made based on that reading. This causes the farmers to lose money. This situation provided the motivation for an innovation. Rajamani now uses the device in his farm while selling Cassava. The device is an excellent example of product fusion where the innovator has picked up the manual machine and fitted it with a digital weighing scale. He then goes on to replicate the starch point scale digitally within the equipment. At the point of field visit he had been using this device for 4 years.

Rajamani has replicated the manual process on a digital scale with an enhanced design which reduces the number of pans being used. One is also not required to manually shift the tapioca from one pan to another as the leaver is used to submerge the tuber in or remove it from water. While the innovation was conceived and designed by Rajamani, he required help from his brother who worked in an electrical shop to design the digital scales. 
The total cost of construction incurred by the innovator for a single piece of the equipment was ₹ 16,000 (approx. € 270). He self-financed the innovation and has had this product since 2007 when he first developed its prototype. He did not face a lot of financial difficulties while developing the prototype. This is a significant innovation for the entire community as now the farmers can get a reliable measure of the quality of their crops and are armed with this information during the procurement process.

\subsection{Summarizing Analysis of the Case Studies}

The previous segment allows us to get a comprehensive narrative of grassroots innovations. This segment contains a combined analysis of these innovations. The trends identified here are then applied to the complete sample which has been gathered during the field trip. Table 2 summarizes the details of the case studies.

\begin{tabular}{|l|l|l|l|l|}
\hline & Case 1 & Case 2 & Case 3 & Case 4 \\
\hline Name & $\begin{array}{l}\text { Mansukhbhai } \\
\text { Prajapati }\end{array}$ & $\begin{array}{l}\text { M. } \\
\text { Sadhasivam }\end{array}$ & K.S. Sudheer & S.Rajamani \\
\hline $\begin{array}{l}\text { Number } \\
\text { innovations }\end{array}$ & 2 & 3 & 2 & 1 \\
\hline Gender & Male & Male & Male & Male \\
\hline Formal Education & $10^{\text {th }}$ Standard & $12^{\text {th }}$ Standard & $10^{\text {th }}$ Standard & $\begin{array}{l}12^{\text {th }} \\
\text { Standard }\end{array}$ \\
\hline Profession & Potter & Farmer & Driver & Farmer \\
\hline $\begin{array}{l}\text { Prior } \\
\text { Experience }\end{array}$ & Yes & No & No & No \\
\hline Type of innovation & Radical & Radical & Incremental, \\
Radical & Radical \\
\hline
\end{tabular}




\begin{tabular}{|l|l|l|l|l|}
\hline $\begin{array}{l}\text { Impact of } \\
\text { innovation }\end{array}$ & $\begin{array}{l}\text { Cost, Efficiency, } \\
\text { Usability }\end{array}$ & $\begin{array}{l}\text { Cost, } \\
\text { Productivity }\end{array}$ & $\begin{array}{l}\text { Comfort, } \\
\text { Productivity, } \\
\text { Usability }\end{array}$ & Efficiency \\
\hline $\begin{array}{l}\text { Change in product } \\
\text { cost achieved }\end{array}$ & $-72 \%$ & $-52 \%$ to $-63 \%$ & $51 \%$ & N/A \\
& & & \\
\hline
\end{tabular}

Table 2: Comparison of the Case Studies. Source: Self-Construction

Table 2 allows us to analyze the preliminary trends which could emerge from this data. All four innovators in these case studies were men. Of the four grassroots innovators, two had the maximum number of 12 years of formal education. Sadhasivam who had the maximum number of years of formal education also had the maximum number of innovations. Does this mean that those with more number of years of formal education are more inclined to innovate serially? What can also be observed from this small sample is that most of the grassroots innovators are farmers. This poses the question: What are the professions of grassroots innovators?

All but one of the innovations can be classified as radical. A product is classified as a radical product if it is previously unobserved within the community of the innovator and is perceived as significantly new by the formal markets. An incremental grassroots innovation would refer to small but significant modifications to already existing products used within the grassroots innovator's community. Using this definition, only the coconut de-husking machine was a significant improvement of an already existing product. Thus, it was classified as in incremental innovation. All the other products were radical innovations.

We also observe that only one innovator had prior work experience in the formal industry where as all the other innovators were confined to one profession. But we also observe that the cost reduction achieved by the innovator with multiple industry experiences is the highest. Could the skills picked up by working in different industries impact the reduction in cost of the innovation?

Finally, we see that all these grassroots innovations have impacted the cost, efficiency, productivity, usability or comfort of the products or the processes they were used in. Is this an all-inclusive classification of the possible impacts of grassroots innovations or could grassroots innovations impact products across more dimensions? Are innovations with 
multiple impacts costlier or are they cheaper than innovations with single impact? Here in this sample, innovators with less number of years of formal education have been able to produce more dimensions of impact in their innovations. Is there any reason why this might be so?

Figure 3 depicts steps followed by the respective inventors in each step of the innovation process, as defined by Herstatt and Verworn (2004). This Grassroots Innovations Development Process illustrates some of the possible pathways for grassroots inventors. It also shows that grassroots innovations may take recourse to a sort of "open innovation" by availing assistance from their circle of acquaintances. One interesting point in the cases discussed here is that many of the inventions are yet to be introduced to the market; underlining the fact that commercialization remains a major problem for grassroots inventors.

\begin{tabular}{|c|c|c|c|c|c|}
\hline Case 1 & $\begin{array}{l}\text { Trial \& } \\
\text { Error }\end{array}$ & $\begin{array}{l}\text { Focus on } \\
\text { Materials }\end{array}$ & $\begin{array}{c}\text { Assistance } \\
\text { availed }\end{array}$ & $\begin{array}{c}\text { Assistance } \\
\text { availed }\end{array}$ & Introduced \\
\hline Case 2 & Sketches & $\begin{array}{c}\text { Focus on } \\
\text { Design }\end{array}$ & $\begin{array}{l}\text { Assistance } \\
\text { availed }\end{array}$ & $\begin{array}{c}\text { Assistance } \\
\text { availed }\end{array}$ & $\begin{array}{l}\text { Yet to be } \\
\text { Introduced }\end{array}$ \\
\hline Case 3 & Trial \& Error & $\begin{array}{l}\text { Focus on both } \\
\text { Materials and } \\
\text { Design }\end{array}$ & $\begin{array}{c}\text { No assistance } \\
\text { was availed }\end{array}$ & $\begin{array}{c}\text { No assistance } \\
\text { was availed }\end{array}$ & $\begin{array}{l}\text { Yet to be } \\
\text { Introduced }\end{array}$ \\
\hline Case 4 & $\begin{array}{l}\text { Process } \\
\text { Study }\end{array}$ & $\begin{array}{l}\text { Focus on } \\
\text { Design }\end{array}$ & $\begin{array}{c}\text { Assistance } \\
\text { availed }\end{array}$ & $\begin{array}{c}\text { Assistance } \\
\text { availed }\end{array}$ & $\begin{array}{l}\text { Yet to be } \\
\text { Introduced }\end{array}$ \\
\hline
\end{tabular}

Figure 3: Grassroot Innovations Development Process

All these observations and questions require us to carry out a detailed study with a larger sample size of grassroots innovators. Such an analysis holds the key to identifying established and possibly more generalizable trends, if any, within the field of grassroots innovations. The next segment deals with such an analysis.

\section{Characterizing Grassroots Innovations}

The previous case studies illustrated the complexities involved in grassroots innovation process. Informal knowledge, traditional skills, personal networks, private capital and contextual insights all cross paths to evoke grassroots innovation. This segment presents the 
analysis of the data gathered on the field. The information is then used to highlight certain trends which could form the agenda for future research.

\subsection{Gender \& Age of Grassroots Inventors}

Most of the grassroots innovators in our survey were male. Of the total of 32 innovators which our survey captured, 29 innovators were male and only 3 of the innovators were female. This trend is consistent with the observations made in the case study where all the four innovators are male.

It is also interesting to note that while the male innovators were spread across various professions (discussed in detail later on), all three female grassroots innovators were students, and in the age group of 11 to 20 years. One of the possible reasons for the low level of female grassroots innovators solving technological problems, may be the social constraints imposed on women, which have "prevented them from acquiring blacksmithy or carpentry tools" (Gupta et al, 2003: 981). While our results statistically support the dominance of male innovators over female innovators at the grassroots, further studies are required to foster a better understanding of such engendering and creative capacities.

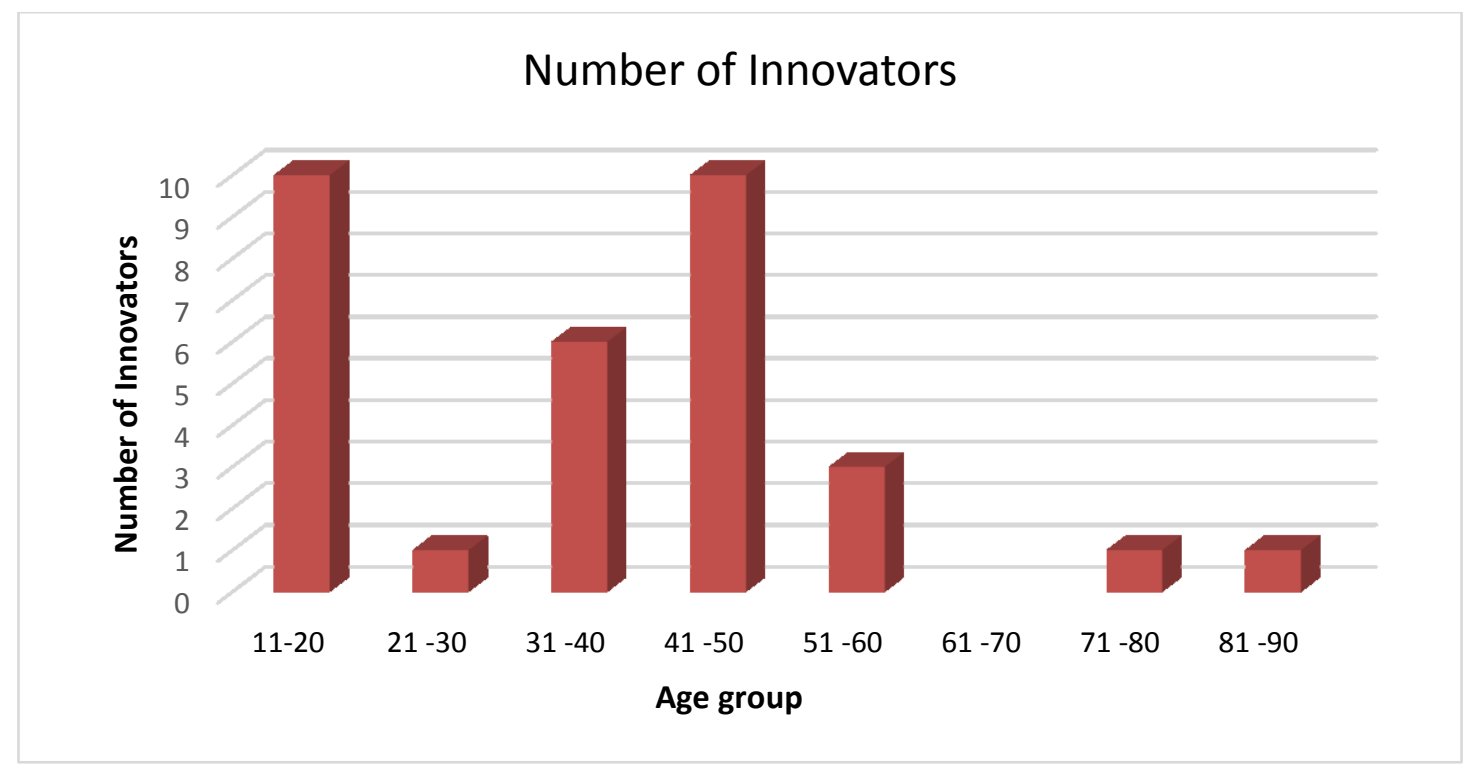

Figure 3: Age-Groups of Grassroot Inventors

The field data contained the age details of 32 grassroots innovators and as can be seen in Figure 3, a majority of the grassroots innovators can be clubbed into two age groups, i.e. between 11 to 20 years and between 41 to 50 years. All of the innovators who fell between the 11 to 20 age brackets were students who were still attending their local village schools, potentially indicating the role of (formal) education in promoting innovation capability and 
innovative behavior. The two octogenarian grassroots innovators in the sample relied on the traditional practices and knowledge rooted in the community to execute their respective innovations. This trend is also consistent with the observations which we made during the case study where the innovators in all the four cases fell between the age brackets 41-50 years.

\subsection{Formal Education and Grassroots Innovations}

Education plays a significant role in development. How does formal education impact grassroots innovations?

\section{Formal Education \& Grassroots Innovations Sample Size, N=30}

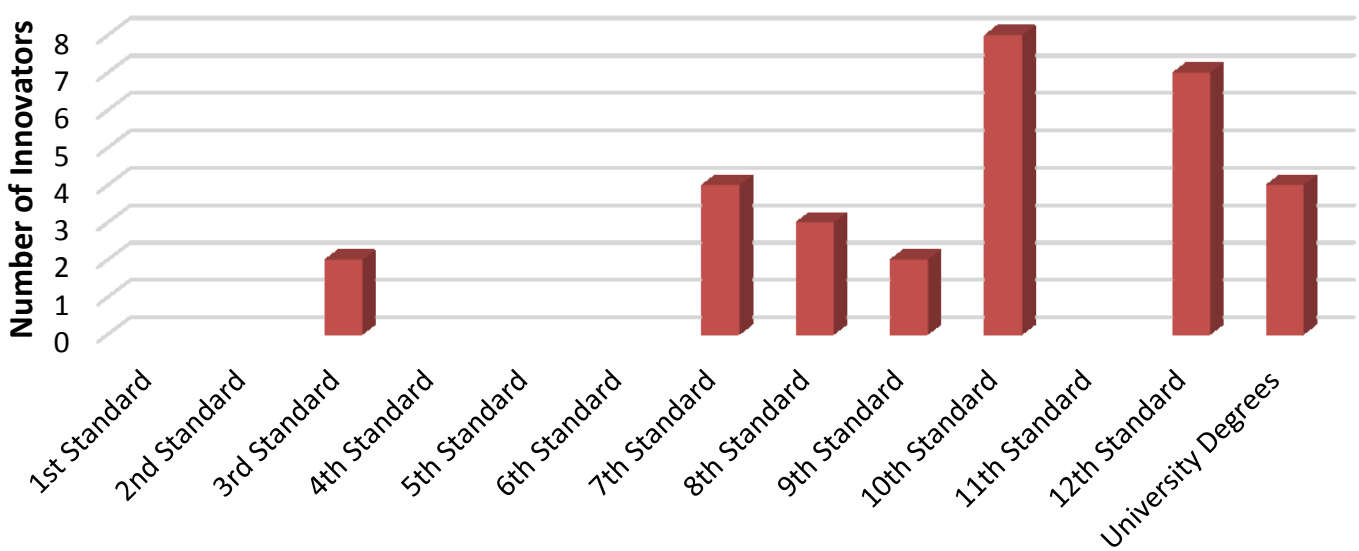

Figure 4: Formal Education of Grassroot Inventors

Figure 4 depicts the impact of education on grassroots innovators. The data reveals that most of the grassroots innovators have received at least 7 years or more of formal education. There were 8 innovators with 10 years of formal education and 7 who had 12 years of formal education. There were only 4 grassroots innovators with University degrees.

Therefore, in general, we can observe a positive correlation between the number of years of formal education and grassroots innovations. What is also interesting is the absence of a significant number of grassroots innovators with college degrees. This could be because, a university degree allows a candidate to enter the formal employment market and work for firms where his or her skills are acknowledged through formal channels. Since necessity was always a key trigger for grassroots innovations, the incentive to innovate at a grassroots level decreases with the increase of formal education. 
It was also observed that the innovators with the maximum number of innovations ( 3 each), both had 12 or more years of formal education. However, the impact of the innovator who was less educated among the two was greater and the products more radical. It's also important to point out that all innovators with two or more innovations had 10 or more years of formal education.

When this data is jointly analyzed with the data about the age, we find that irrespective of the age, grassroots innovations require an average threshold of 8.5 years of formal education.

\subsection{Occupations and Grassroots Innovations}

When they are not busy innovating, what exactly do these grassroots innovators do for a living? A quick snapshot of the classification of the grassroots innovators by their professions can be found in Figure 5 .

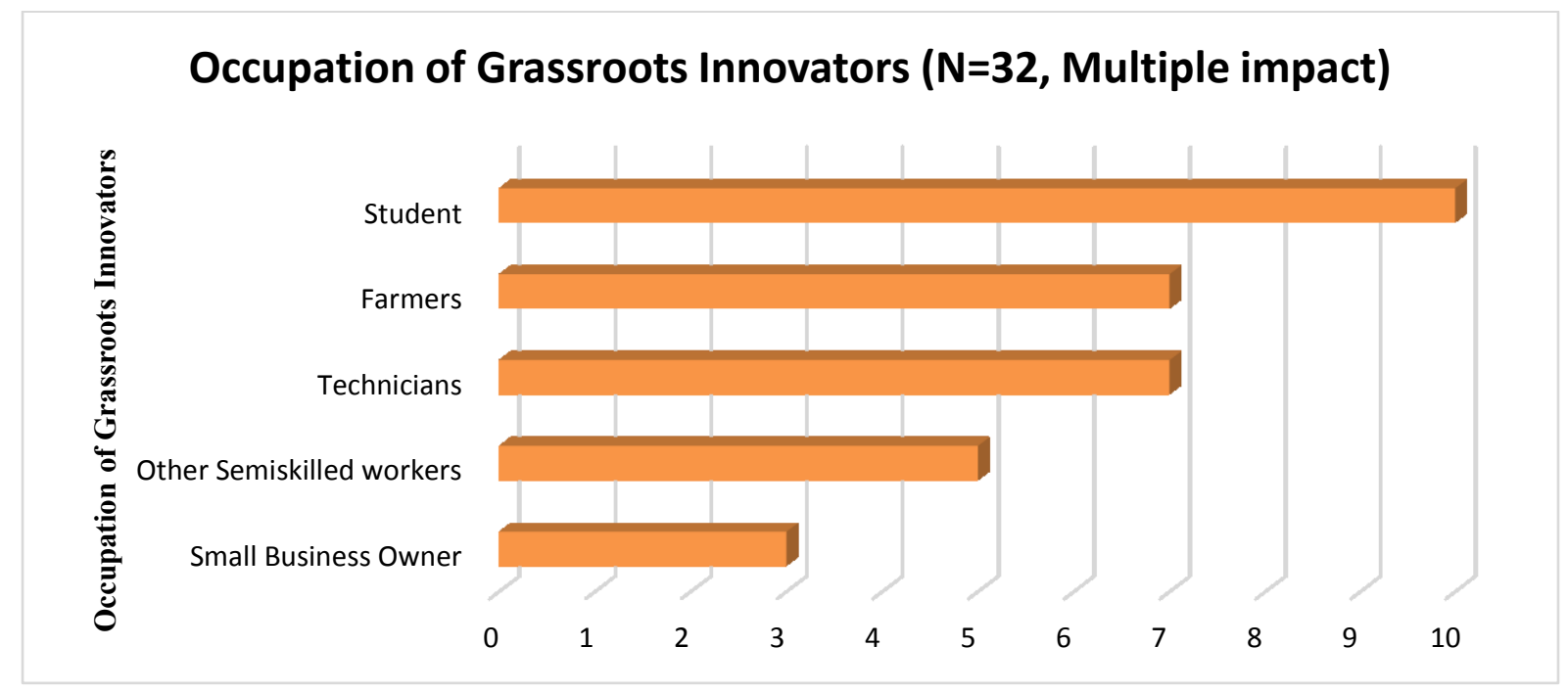

Figure 5: Occupation of Grassroot Inventors

Thus, we can see that the majority of the grassroots innovators in this sample are students (31\%). Farmers and technicians jointly occupy the second spot and each constitutes $22 \%$ of the innovators in this survey. Other semi-skilled workers and small business men formed $16 \%$ and $9 \%$ of the innovators respectively.

Here it's essential to point out that all the auto mechanics, electrical mechanics and electronics mechanics were combined into the category of technicians. Auto mechanics were here the most dominant category comprising $71 \%$ of the technicians. Other semi-skilled workers collectively refer to the people employed as potters, tailors, drivers and traditional 
stove makers. This is an extremely fragmented category and provides the vibrancy and diversity to the kinds of grassroots innovations which we encountered.

A quick comparison of the average formal education received by the innovators classified by profession was carried out. The results for this (Figure 7) make an interesting discussion.

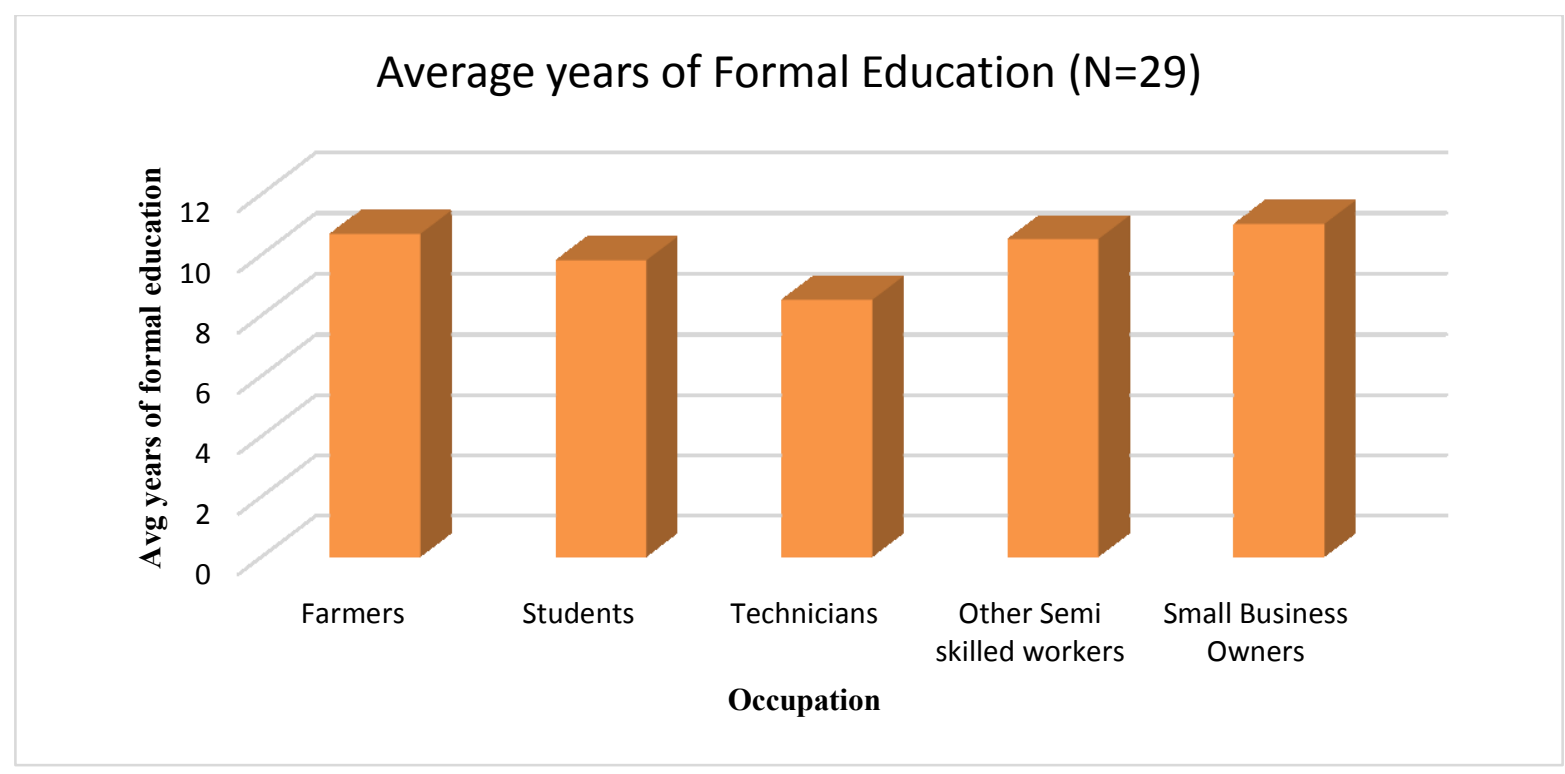

Figure 7: Average years of formal education vis-à-vis occupation

Form Figure 7 we can see that if students are ignored, then, probably not surprisingly, the small business owners are the beneficiaries of maximum number of years of formal education. Their average years of formal education are 11 years. This is slightly more than the average for the farmers at 10.7 years. This information could suggest why a combination of their innovativeness and base education has not helped them commercialize their respective innovations. Of the business owners in the survey, only one small business owner innovator is running a business based on his innovations. The technicians are the innovators with the least average years of formal education but what they lack for in theory, they make up for it with the on the job experience. Most of their innovations are solutions to persistent problems which they encounter in their daily lives.

\subsection{Sources of Grassroots Innovations}

To gain a better understanding of the practices involved in grassroots innovation, we mapped the innovator's knowledge in his base domain (profession) and analyze its transfer to the target domain (field of impact of the innovation). In order to do this, we used the framework developed by Kalogerakis, Lüthje and Herstatt (2010). Since, grassroots innovators have a limited amount of formal knowledge to carry out their innovations, they rely on several 
processes to transfer their base knowledge to the target domain or the innovation. The complexity of the processes can be gathered from the case studies present at the beginning of this section. However, it is clear that the process being adopted allows the innovator to learn new skills, as well as induces new learning. Both these traits are vital strands of the “analogical thinking process" (Kalogerakis et al, 2010).

Grassroots innovations involve transfer of knowledge for both, (a) technological solution or functional principle, and (b) shapes, designs and arrangements. Here it can be observed that a majority of the radical innovations occur when the grassroots innovators applies his skills to another product category. An example of a case in this category is the Power driven Harvesting and threshing machine in which the farmer uses his knowledge of farming into the target domain of auto mechanics. A lot of tacit, functional knowledge has gone into the design of the innovation. A similar process occurs in the case of 'Electric Rocking bed with auto timer' where a small textile business owner and an electrician combined their skills to design a solution which fell in neither of their domains.

Data showed that an increase in the transfer distance between the base and the target domain has a positive impact on the novelty of the solution. $79 \%$ of the identified radical grassroots solutions fell in the "another product category" or the "non-product knowledge domain". However, what is less understood is the reason why the innovators chose to innovate in their respective domains. The next section discusses the triggers for these innovations.

\subsection{Innovation Triggers}

Over the years, scholars have often drawn a distinction between voluntary or intrinsic motivation and "goal directive" or extrinsic motivation (Deci, 1971). This distinction makes it tempting to apply this theory to identify the underlying reason for grassroots innovators to innovate. Prima facie, a task riddled with uncertainties should be challenging to provide the motivation to innovate. Therefore intrinsic motivation could be an obvious driver for grassroots innovations. But, it has also been argued by some scholars that the "perceived payoff of an innovation" may be a key determinant of his/her decision to innovate (see, Bhaduri and Kumar, 2009: 7). Grassroots innovation, as discussed earlier, is a complex phenomenon, driven by interplay of several multi-dimensional forces located in the surroundings of the inventor. 
Innovation triggers facilitate the engagement between 'how to innovate' and 'why innovate' and the outcome of the dialogue triggers the grassroots innovation. Figure 8 lists the grassroots innovation triggers identified in this study.

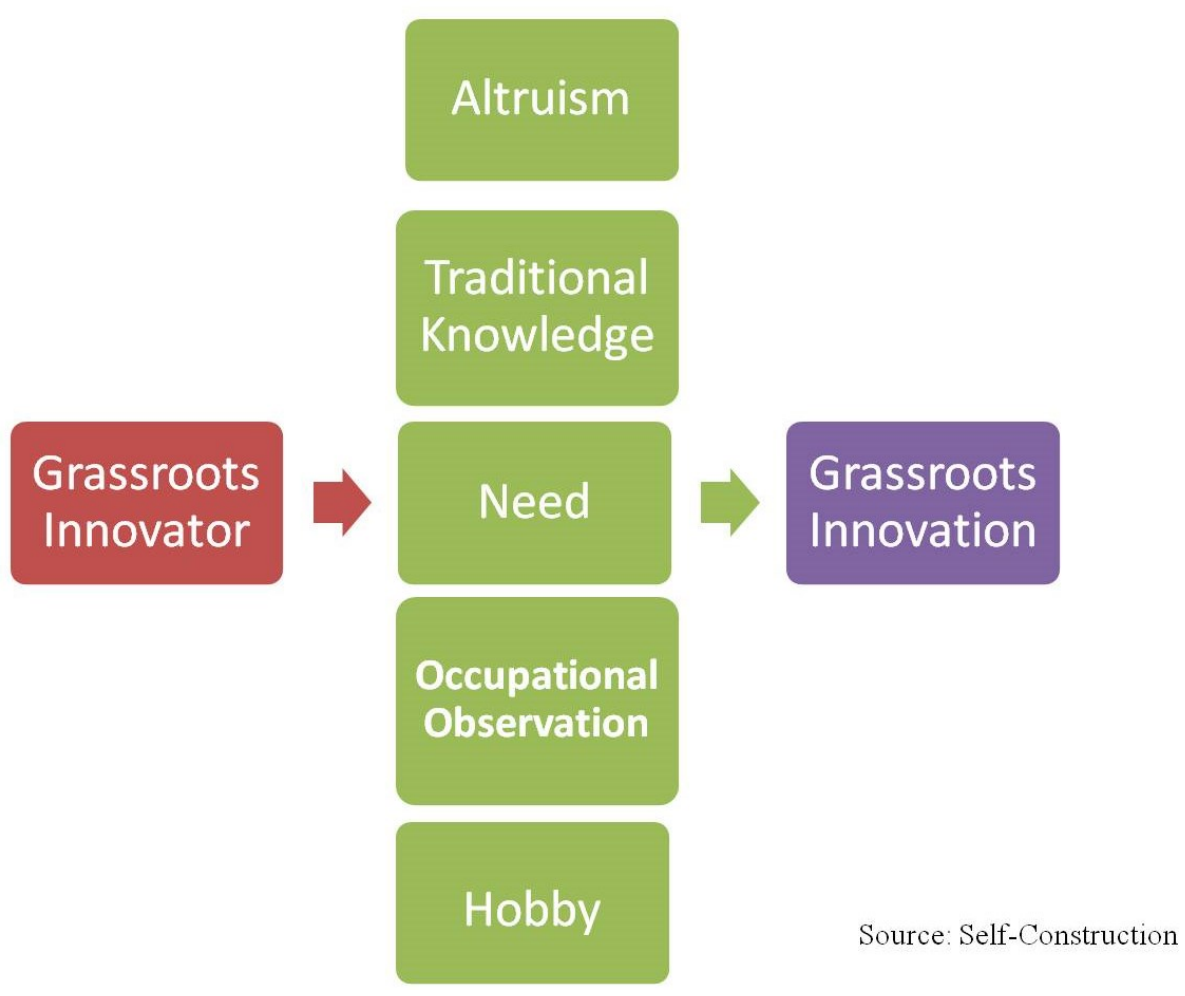

Figure 8: Triggers of Grassroot Innovations

We analyzed these triggers to identify their role in individual grassroots innovations and the results are summarized in Figure 9.

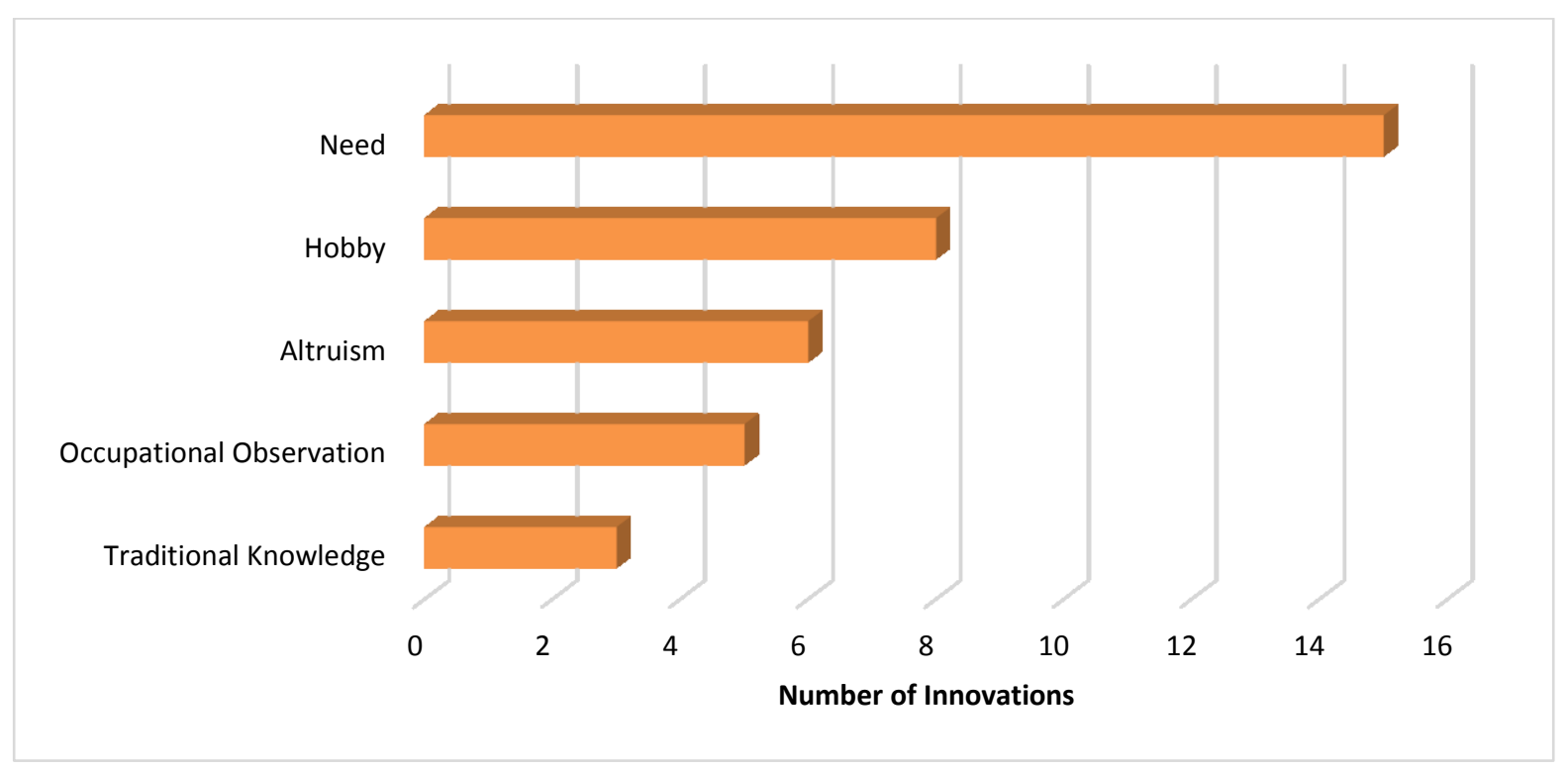

Figure 9: Impact of Individual Triggers on Grassroots Innovations 
It appears from Figure that most often it is a personal need which motivates a grassroots innovator to create a solution. Other factors, such as a hobby or the desire to help someone in his or her daily life (altruism), are also important drivers of grassroots innovations. At other times the innovator observes some needs/opportunities in his professional life and tries to make use of them by coming with an attractive product or service. Finally, the desire to utilize and preserve traditional knowledge can also act as a trigger to innovations at the grassroots.

When these triggers are used to compare the radicalness of innovations, it was found that of the 14 innovations perceived as radical, only 6 innovations stemmed from (personal) needs. Of these 6 , only two were driven by a business requirement. There were 5 radical innovations which emerged from the hobbies of the innovator, 2 from altruism and 1 from traditional knowledge. It shows that a perceived personal need does not necessarily have to be the sole source of motivation for a radical innovation at the grassroots.

\subsection{Impact of Grassroots Inventions}

So why should grassroots innovations draw attention from beyond the communities they impact? This question is best answered by analyzing the impact of the grassroots innovations. The dimensions impacted by grassroots innovations are summarized in Figure 106:

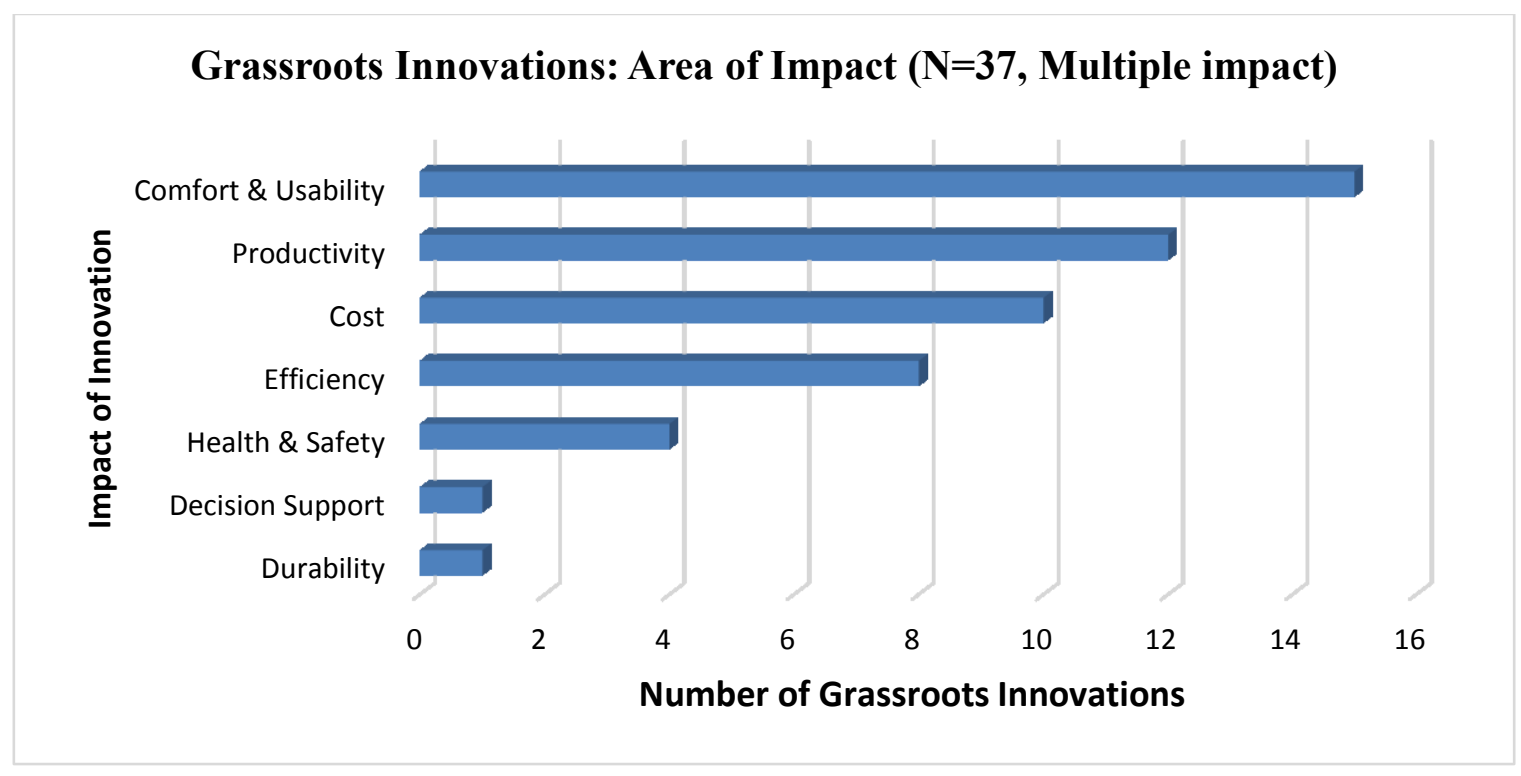

Figure 106: Area of impact of Grassroots Innovations

We can therefore see that a majority of the grassroots innovations revolved around enhancing the comfort and usability of existing products or solutions. Productivity was the next most impacted dimension followed by cost. So contrary to popular belief, grassroots innovations 
are not merely low-cost products competing on cost alone. They can be perceived as products which enhance the utility of a particular product.

It would be also worthwhile to carry out a classification of the grassroots innovations into radical and incremental innovations, based on how they are perceived by the local communities from which they emerge. From the sample, we calculate that $38 \%$ of all the observed innovations may be considered radical innovations and the remaining $62 \%$ of the innovations as incremental. The sample was then analyzed as per these classifications to see if the dimensional priorities differ for radical grassroots innovations vis-à-vis incremental grassroots innovations. Figure summarizes the difference in priorities of these dimensions.

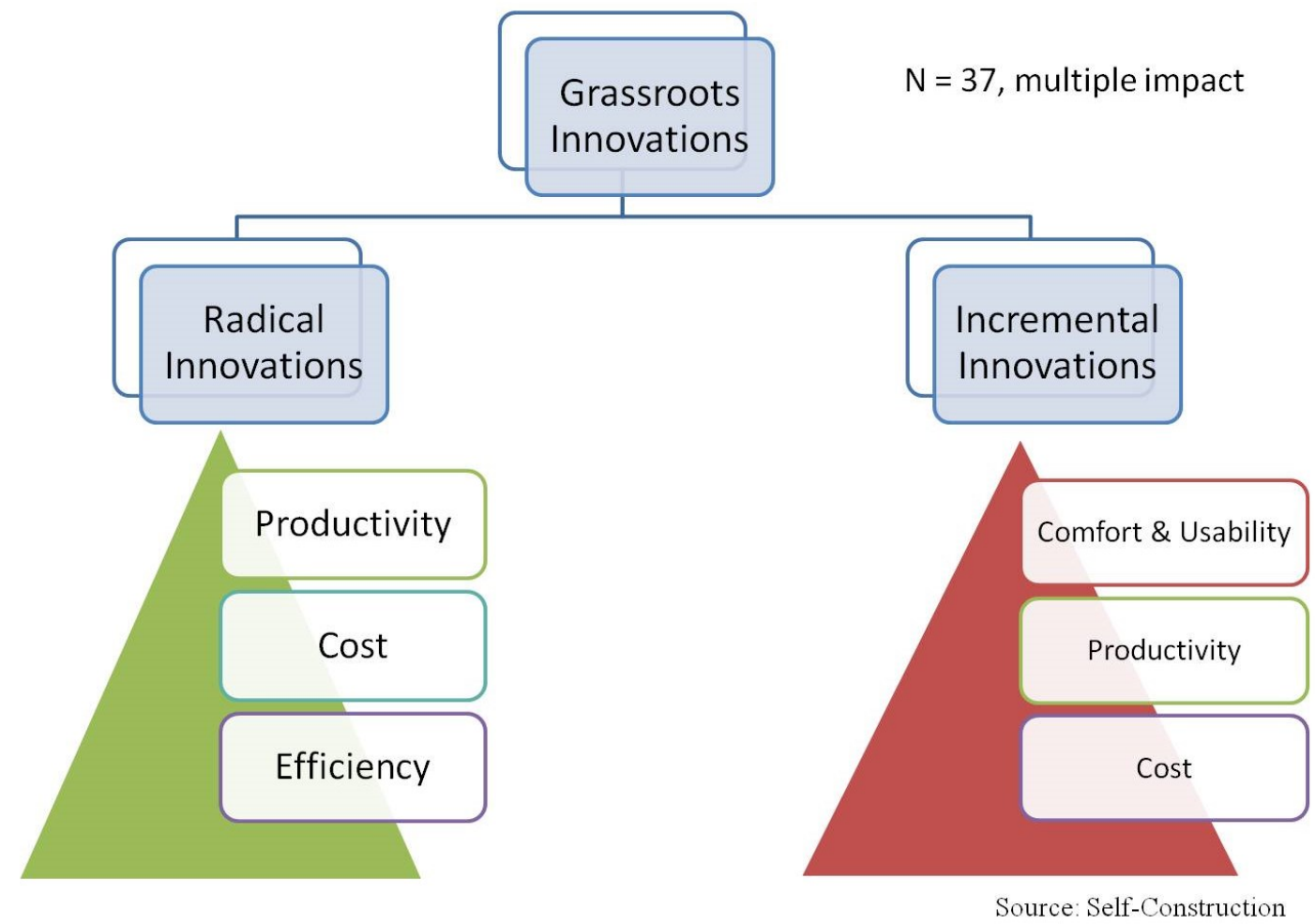

Figure 11: Difference in dimensional priorities, Grassroot Innovations

We can thus observe that for radical innovations, productivity, cost and efficiency were the most important criteria in that order of preference, whereas for the incremental innovations, comfort and usability were by far the overwhelming features of the innovations. This was followed by productivity and cost. This goes on to highlight that product cost is definitely an important feature which grassroots innovators consider while they innovate.

It was also observed that the grassroots innovators with radical innovations had on an average 10.7 years of formal education when compared to incremental grassroots innovators that had 
9.9 years of formal education. This observation further highlights the potentially important role formal education plays in the grassroots innovations process.

While analyzing this data across professions, farmers and other semi-skilled workers jointly had the most number of radical innovations at 3 innovations each. This is in complete agreement with the previously observed trend where farmers and other semi-skilled workers had a higher level of average formal education. This probably also explains why these people are more inclined to innovate radically.

\subsection{Cost of Grassroots Inventions}

Of the various benefits accrued from innovations, cost is an important dimension. Product costs play an important role in determining the commercial viability of an innovation. Therefore, we carried out a detailed analysis of the cost and its impact on grassroots innovations. We analyzed data for 18 grassroots innovations, and gathered information about the competing product along with its price to perform this analysis.

Of the 18 grassroots innovations analyzed, only three innovations were more expensive when compared to similar competing products. Of the three, namely the universal gear joint leaver actuator, the foot pedal operated coconut de-husker and the domestic arsenal removal water filter, two i.e. the universal gear joint leaver actuator and the foot pedal operated coconut dehusker were vastly superior in quality when compared to the existing products in the market. A mini survey conducted among the users of these innovations revealed that they were willing to pay this price premium to acquire these products. No such information could be gathered for the water filter.

About $83 \%$ of the grassroots innovations were able to offer their users the desired core functionality at a lower price. The reduction in cost varied from $25 \%$ to $72 \%$. The radical innovations achieved a price reduction in the range of $51 \%$ to $71 \%$, whereas the incremental innovations achieved a price reduction in the range of $25 \%$ to $30 \%$.

Next we looked at the variation of cost along the dimensions of productivity and comfort \& usability. These two dimensions were chosen because both these dimensions were the top priority for radical and incremental grassroots innovations respectively. The analysis showed that only one innovation which increased productivity was more expensive than the existing product. This observation lends support to the claim that grassroots innovations can be both superior as well as more affordable when compared to existing products in the. An analysis of 
the relation between comfort and utility with respect to product cost showed that all products except one were able to enhance utility while significantly reducing the cost. The reduced cost as a percentage varies from $20 \%$ to $85 \%$ suggesting great potential for innovation commercialization. These observations also seem to be in line with a study by Rao (2013), who found similar patterns of cost reduction in case of 13 frugal products.

\subsection{Sources of Finance for Grassroots Inventions}

Undertaking an innovation is a significant financial consideration for a grassroots innovator. Innovations are associated with uncertainty and current government support programs are not adequate to support such endeavors. The graphic below shows how grassroots innovators have been supporting their endeavors.

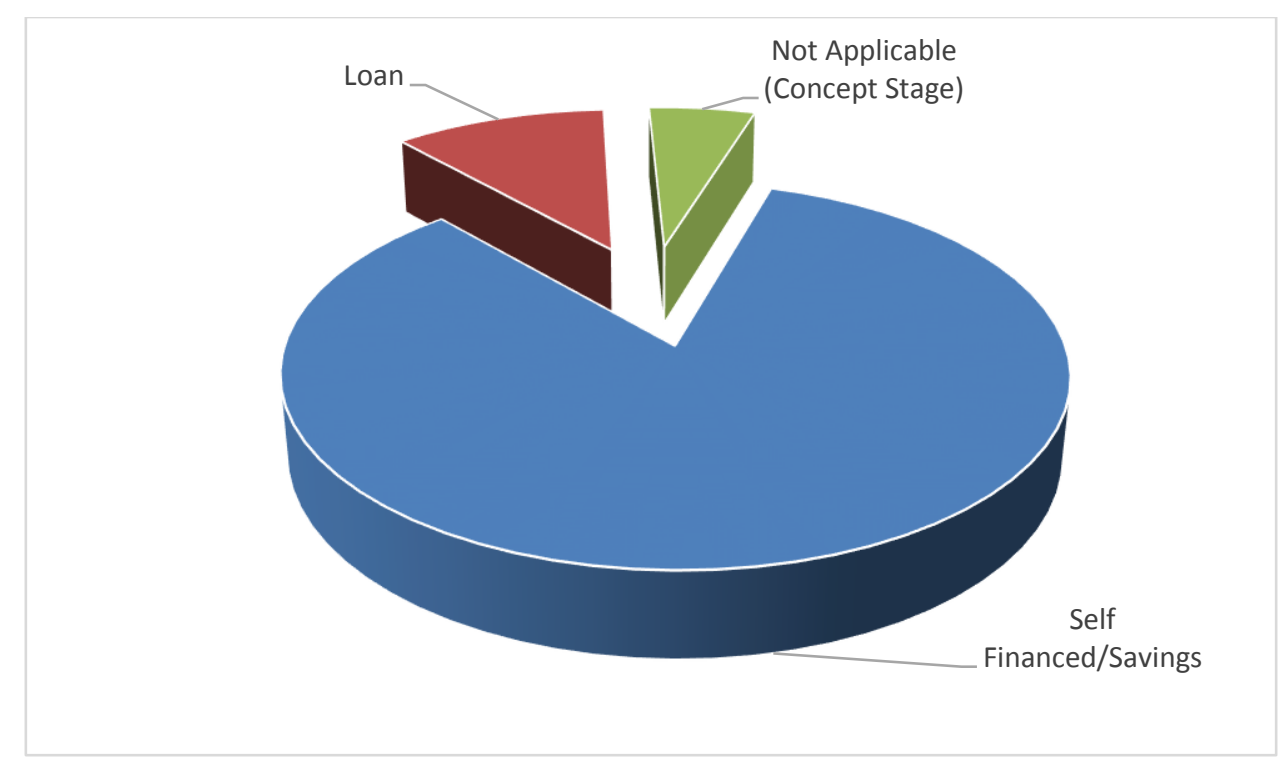

Figure 12: Sources of Finance

It can be seen that most of the grassroots innovators do not enjoy any kind of monetary support to carry out their innovation endeavors. Some of the innovators we spoke to have expressed their anguish and frustration when their innovations get stalled due to lack of funds. K.S Sudheer, from the case study had to utilize the prize money he won as recognition for some of his innovations to fund future developments. Another innovator, who had built an amphibious car too complained about how difficult it was to access a bank loan despite being creditworthy. There were, undoubtedly, instances of inventors getting support from government institutions involved with agriculture and rural development. But there seems to be a need for action by policymakers to better support such innovative activities at the grassroots. 


\section{Summary \& Conclusions}

The analysis above allows us to identify some preliminary patterns, which are presented in the following:

a) Grassroots innovations in India seem to be dominated by male innovators (91\%). Social constraints imposed on women as a consequence of cultural institutions might be one reason behind the apparently low level of participation of female grassroots innovators. Possible is also that their inventions, for instance, if they are done for some household application, do not come to public notice as often as those of their male counterparts.

b) The study found a positive correlation between the number of years of formal education and grassroots innovations. Grassroots innovations seem to "require" an average threshold of 8.5 years of formal education.

c) If student innovators are left out, then farmers and technicians jointly constitute $22 \%$ each of grassroots innovators surveyed. Other semi-skilled workers and small business men formed $16 \%$ and $9 \%$ of the innovators respectively.

d) The study reveals that an increase in the transfer distance between the base and the target domain has a positive impact on the novelty of the solution. $79 \%$ of the radical grassroots solutions fell in the "another product category" or the "non-product knowledge domain".

e) Personal needs, hobbies, occupational observation, traditional knowledge and altruism were identified as grassroots innovations triggers.

f) For radical innovations, productivity, cost and efficiency were the most important areas of impact criteria in that order of preference, whereas for the incremental innovations, comfort and usability were by far the overwhelming features of the innovations. This was followed by productivity and cost.

g) About $83 \%$ of the grassroots innovations were able to offer their users the desired core functionality at a lower price.

h) Eighty-four per cent of grassroots innovations were self-funded by the innovators. Only $11 \%$ of the innovators had access to loans to fund their innovations. 
This study contributes to the nebulous but evolving research about grassroots innovations. It seeks to enrich the innovation academic debate as well as suggests the possibilities such innovations hold. We have argued that grassroots innovations are neither imitations of the BOP innovations philosophy nor are they mere mutations of the frugal innovation paradigm. In fact, grassroots innovations have been articulated as "innovation bricolage" where we link the theory from anthropology with product innovation.

Understanding the emerging patterns of grassroots innovations should inform policy makers on "how value can be created from [grassroots] resources, which would enable them to make "better-informed decisions" while allocating resources which support the grassroots paradigm]" (Seelos and Mair, 2007: 61). The data for this research is drawn from a single country, India. Further research set in various emerging economies is required to analyze and compare the patterns which we isolated in this study. A comparison of the various patterns in different setting could further enrich and inform the research in grassroots innovations.

The case studies in this thesis contribute to a better understanding of the complexities associated with grassroots innovations and allow scholars to perceive their limits and challenges. While researchers in management and development economics have always called for specific strategies to pull the poor into a market economy (Karnani, 2007), research with strategies in which the poor are treated as producers is limited. Our work hopefully contributes to reducing this literature deficiency.

The ability of managers to integrate resources that create "more value than the cost of the resources" is vital to economic success (Seelos and Mair, 2007: 61). Grassroots innovations, can become, what Seelos and Mair (2007: 61) have called "a source for economically undervalued resources and capabilities". This is akin to unpolished diamonds, whose true worth is revealed when polished. Grassroots innovators, just like "adequate BOP partners", "may thus constitute a scarce resource, and identifying them early may enable companies to preempt market access and reap the benefits of first-mover advantage" (Seelos and Mair, 2007: 63).

Grassroots innovations can also complement the BOP and frugal innovation strategies to realize to help alleviate poverty, foster sustainable economic development and reach the "Millennium Development Goals" of the United Nations. The funding provided for official development assistance can be utilized to overcome the important hurdles for grassroots innovations. 
Operationalizing Grassroots Innovations requires the coming together of various institutions, each of which plays a clearly defined role in the process. Managing the roles of the grassroots innovators, government institutions, private enterprises and non-governmental organizations (NGOs) is complex and requires clear but simple regulations. Such a framework may require time and effort to foster but that shouldn't deter policy makers from acting. To cite the instructions that Hubert Lyautey, a French general, according to an article in The Economist (2011) gave to his gardener: "if a tree takes 150 years to mature, that's all the more reason to plant it as soon as possible".

A better understanding of grassroots innovations would not only ensure a freer world where skills and intellect are rewarded, in some cases handsomely, but would also tackle the most unfair sorts of income disparity, and allow more people to move socially upwards by ensuring their participation in wealth creation. We hope that this study will help this subject get its due.

\section{Acknowledgements}

Rajnish Tiwari would like to thank Claussen Simon Foundation for supporting his research at TUHH with a generous grant.

\section{Bibliography}

Abernathy, W. J. and K. B. Clark (1985): "Innovation: Mapping the winds of creative destruction," Research Policy 14(1): 3-22.

Agtmael, A. v. (2007): The Emerging Markets Century: How a New Breed of World-class Companies is Overtaking the World, New York, Free Press.

Baker, T., A. S. Miner, and D. T. Eesley (2003): "Improvising Firms: Bricolage, Retrospective Interpretation and Improvisational Competencies in the Founding Process," Research Policy 32: 255-276.

Baker, T. and R. E. Nelson (2005): "Creating Something from Nothing: Resource Construction through Entrepreneurial Bricolage," Administrative Science Quarterly 50(3): 329-366. 
Bhaduri, S. and H. Kumar (2009): "Tracing The Motivation To Innovate: A Study of 'Grassroot' Innovators In India ", Working Paper \# 0912, Jena, Max Planck Institute of Economics, Evolutionary Economics Group.

Davis, M. S. (1971): "That's Interesting! Towards a Phenomenology of Sociology and a Sociology of Phenomenology," Philosophy of the Social Sciences 1(4): 309-344.

Deci, E. L. (1971): " Effects of externally mediated rewards on intrinsic motivation," Journal of Personality and Social Psychology 18(1): 105-115.

Economist (2011, June 2): "Wanted: chief firefighter," The Economist, Retrieved July 19, 2016.

Garud, R. and P. Karnøe (2003): "Bricolage versus breakthrough: distributed and embedded agency in technology entrepreneurship," Research Policy 32: 277-300.

Geels, F. W. (2004): "From sectoral systems of innovation to socio-technical systems: Insights about dynamics and change from sociology and institutional theory," Research Policy 33(6-7): 897-920.

Grieve, R. H. (2004): "Appropriate Technology in a Globalizing World," International Journal of Technology Management and Sustainable Development 3(3): 173-187.

Gupta, A. K. (2000): Grassroot Innovations for Survival, LEISA India, 2 (2) July: 20-21.

Gupta, A. K. (2006): "From Sink to Source:The Honey Bee Network Documents Indigenous Knowledge and Innovations in India," Innovations 1(3): 49-66.

Gupta, A. K. (2008, February 28): "What can we learn from green grassroots innovators: Blending reductionist and holistic perspectives for sustainability science," Lecture delivered at Center for International Development, Harvard's Sustainability Science Program, Harvard University, $\begin{array}{lllll}\text { Retrieved } & \text { July } & 14, & 2016, & \text { from }\end{array}$ www.iimahd.ernet.in/users/anilg/files/Articles/What $\% 2520 \mathrm{can} \% 2520 \mathrm{we} \% 2520$ learn $\% 2520$ from $\%$ 2520 green $\% 2520$ grassroots $\% 2520$ innovators.doc.

Gupta, A. K. (2010): Grassroot Green Innovations for Inclusive, Sustainable Development,in: A. López-Carlos, The Innovation for Development Report 2009-2010: Strengthening Innovation for the Prosperity of Nations, Hampshire, Palgrave Macmillan: 137-146.

Gupta, A. K., R. Sinha, D. Koradia, R. Patel, et al (2003): "Mobilizing grassroot' technological innovations and traditional knowledge, values and institutions: articulating, social and ethical capital," Futures 35(9): 975-987. 
Gupta, A. K., R. Sinha, D. Koradia, T. N. Prakash, et al (2001): Building upon Grassroots' Innovations: Articulating Social and Ethical Capital, World Social Forum Workshop, Porto Alegre, Brazil.

Hart, S. and S. Sharma (2004): "Engaging fringe stakeholders for competitive imagination," Academy of Management Executive 18(1): 7-18.

Herstatt, C. and B. Verworn (2004): The Fuzzy Front End of Innovation,in: EITIM, Bringing Technology and Innovation into the Boardroom, Houndmills, Palgrave MacMillan: 347-373.

Immelt, J. R., V. Govindarajan, and C. Trimble (2009): "How GE Is Disrupting Itself," Harvard Business Review 87(10): 56-65.

Kalogerakis, K., C. Lüthje, and C. Herstatt (2010): "Developing Innovations Based on Analogies: Experience from Design and Engineering Consultants," Journal of Product Innovation Management 27(3): 418-436.

Kaplinsky, R. (2011): "Schumacher meets Schumpeter: Appropriate technology below the radar," Research Policy 40(2): 193-203.

Karamchandani, A., M. Kubzansky, and N. Lalwani (2011): "Is the Bottom Of the Pyramid Really for You," Harvard Business Review 89(3): 107-111.

Karnani, A. (2007): "The Mirage of Marketing to the Bottom of the Pyramid: How the Private Sector can Help Alleviate Poverty," California Management Review 49(4): 90-111.

Kemp, R. and J. Rotmans (2005): The Management of the Co-Evolution of Technical, Environmental and Social Systems,in: M. Weber and J. Hemmelskamp, Towards Environmental Innovation Systems, Heidelberg, Springer: 33-55.

Khanna, T. and K. Palepu (2000): "The Future of Business Groups in Emerging Markets: Long-Run Evidence From Chile," Academy of Management Journal 43(3): 268-285.

Krämer, A. (2015): Low-Income Consumers as a Source of Innovation: Insights from Idea Competitions in Brazilian Low-Income Communities, Wiesbaden, Springer Gabler.

Leff, N. H. (1978): "Industrial Organization and Entrepreneurship in the Developing Countries: The Economic Groups," Economic Development and Cultural Change 26(4): 661-675.

Levi-Strauss, C. (1966): The Savage Mind, Chicago, University of Chicago Press.

London, T. and S. L. Hart (2004): "Reinventing strategies for emerging markets: beyond the transnational model," Journal of International Business Studies 35(5): 350-370. 
Maase, S. and K. Dorst (2010): Emerging Social Entrepreneuship: Exploring the Development Process,in: K. Hockerts, J. Mair and J. Robinson, Values and Opportunities in Social Entrepreneurship, Hampshire, Palgrave Macmillan: 181-199.

Mair, J. and I. Marti (2007): "Entrepreneurship for social impact: encouraging market access in rural Bangladesh," Corporate Governance 7(4): 493-501.

Mair, J. and I. Marti (2009): "Entrepreneurship in and around institutional voids: A case study from Bangladesh," Journal of Business Venturing 24(5): 407-532.

Masse, S. J. and K. Dorst (2007): Exploring the development process of grassroot social entrepreneurship, International Social Entrepreneurship Research Conference 3, Center for Corporate Values and Responsibility (CVR): 1-24.

Nair, A. K., R. Tiwari, and S. Buse (2012): "Emerging Patterns of Grassroot Innovations - A conceptual study based on selected case studies from India ", Working paper No. 70, Hamburg, Institute for Technology and Innovation Management, Hamburg University of Technology.

OECD and Eurostat (2005): Oslo Manual: Guidelines for Collecting and Interpreting Innovation $\underline{\text { Data, }}$ Paris, Organisation for Economic Co-Operation and Development (in joint publication with Eurostat).

Parayil, G. (1996): "The 'Kerala model' of development: development and sustainability in the Third World," Third World Quarterly 17(5): 941-957.

Polanyi, K. (1994): The Great Transformation: The Political and Economic Origins of Our Time, Boston, MA, Beacon Press.

Praceus, S. (2014): Consumer Innovation at the Base of the Pyramid: Emerging Patterns of User Innovation in a Resource-Scarce Setting, Wiesbaden, Springer Gabler.

Praceus, S. and C. Herstatt (2014): Consumer Innovation in the Poor versus Rich World - Some Differences and Similarities, The 6th MEIDE (Micro Evidence on Innovation and Development) Conference, Nov. 21-23, Cape Town (S. Africa), UNU-MERIT, OECD.

Prahalad, C. K. and A. Hammond (2002): "Serving the world's poor, profitably.," $\underline{\text { Harvard Business }}$ Review, 80(9),: 48-58.

Prahalad, C. K. and S. L. Hart (2002): The Fortune at the Bottom of the Pyramid, Strategy + Business, Spring, Issue 22: 2-14.

Prahalad, C. K. and R. A. Mashelkar (2010): "Innovation's Holy Grail," Harvard Business Review 88(7/8): 132-141 
Radjou, N., J. Prabhu, and S. Ahuja (2012): Jugaad Innovation: Think Frugal, Be Flexible, Generate Breakthrough Growth, San Francisco, Jossey-Bass.

Rao, B. C. (2013): "How disruptive is frugal?," Technology in Society 35(1): 65-73.

Schanz, C., S. Hüsig, M. Dowling, and A. Gerybadze (2011): "'Low cost-high tech' innovations for China: why setting up a separate $R \& D$ unit is not always the best approach," $\underline{R \& D \text { Management }}$ 41(3): 307-317.

Schumacher, E. F. (1973): Small is Beautiful: A Study of Economics as if People Mattered, London, Blond \& Briggs.

Schumann, M. (2010): The Miracle: The Epic Story of Asia's Quest for Wealth, New York, HarperCollins.

Seelos, C. and J. Mair (2007): "Profitable Business Models and Market Creation in the Context of Deep Poverty: A Strategic View," Academy of Management Perspectives 21(4): 49-63.

Seyfang, G. and A. Smith (2007): "Grassroots innovations for sustainable development: Towards a new research and policy agenda," Environmental Politics 16(4): 584-603.

Smith, A. (2006): "Green Niches in Sustainable Development: The Case of Organic Food in the United Kingdom," Environment and Planning C: Government and Policy 24(3): 439-458.

Stewart, F. (1987): Macro-policies for appropriate technology in developing countries, Boulder, Westview Press.

Tiwari, R. (2011): 'Doing well by doing good': New opportunities for Indo-German cooperation?, GermanyContact India, Berlin, OWC-Verlag für Außenwirtschaft, October: 17.

Tiwari, R., L. Fischer, and K. Kalogerakis (2016): "Frugal Innovation in Scholarly and Social Discourse: An Assessment of Trends and Potential Societal Implications", Joint working paper of Fraunhofer MOEZ Leipzig and Hamburg University of Technology in the BMBF-ITA project, Leipzig/Hamburg.

Tiwari, R. and C. Herstatt (2014): Aiming Big with Small Cars: Emergence of a Lead Market in India, Heidelberg, Springer.

Tiwari, R., K. Kalogerakis, and C. Herstatt (2016): Frugal Innovations in the mirror of scholarly discourse: Tracing theoretical basis and antecedents, $\underline{R} \& D$ Management Conference, Cambridge, UK.

Vachani, S. and N. C. Smith (2008): "Socially Responsible Distribution: Distribution Strategies for Reaching the Bottom of the Pyramid," California Management Review 50(2): 52-84. 
Von Zedtwitz, M., S. Corsi, P. V. Søberg, and R. Frega (2015): "A Typology of Reverse Innovation," Journal of Product Innovation Management 32(1): 12-28.

Wood, R. C. and G. Hamel (2002): "The World Bank's Innovation Market," Harvard Business Review 80(11): 104-113.

Woodruff, D. M. (1999): Money Unmade: Barter and the Fate of Russian Capitalism, New York, Cornell University Press. 